\title{
Patents and Trademarks: empirical evidence on 'evergreening' from Australia
}

\author{
4th Asia-Pacific Innovation Conference \\ College of Law, National Taiwan University \\ 6 - 7 December 2013 \\ Session 2B: Patenting Strategy
}

\author{
Hazel V J Moir \\ Adjunct Associate Professor \\ Research School of Social Sciences \\ ANU College of Arts \& Social Sciences \\ The Australian National University \\ hazel.moir@anu.edu.au
}

\begin{abstract}
Luigi Palombi
Principal, PalombilP, intellectual property law

(formerly Adjunct Professor of Law, University of Sydney, and

Research Fellow, Regulatory Institutions Network, Australian National University

luigi@palombiip.com
\end{abstract}

(C) Palombi and Moir 2013 (citation encouraged; commercial rights reserved.

This is an ongoing work so if citing, please contact authors for latest version.) 


\title{
Patents and Trademarks: empirical evidence on 'evergreening' from Australia
}

\begin{abstract}
Evergreening is a strategy employed by pharmaceutical companies to extend patent protection around their branded medicines beyond 25 years. It involves claiming modifications to the original active pharmaceutical ingredient (API) as separate "inventions" to extend the period during which pharmaceutically equivalent products are denied market entry. Evergreening refers only to patents taken out by the company owning the original API. Similar improvement/modification patents taken out by other entities are referred to as secondary patents.
\end{abstract}

Such delayed or reduced competition translates into an increase in the cost of healthcare. Brand pharmaceutical companies, of course, argue that these "lifecycle management" patents provide improved health outcomes to the community. They meet the (low) patentability thresholds of novelty, inventiveness and utility. Critics argue that the claimed improved health outcomes are usually either very small or non-existent. If the improved health outcome is negligible the evergreening patents incur a social cost rather than providing a social benefit, as the healthcare costs associated with delayed generic entry are large.

This paper complements the existing empirical evidence by providing an in-depth analysis of a small number of Australian cases where evergreening of brand medicines has occurred. With two exceptions, the cases discussed here involve litigation. Evidence from court cases is useful in identifying rules that encourage or delay generic entry. For some cases PBS data allow partial estimates of the costs of evergreening. Analysis of the case material identifies types of evergreening patents and their market effects. This highlights some key issues in the impact of evergreening on market competition and healthcare costs and points to areas of patent and health policy that need reform.

The paper also looks at the role of trademarks in evergreening by establishing branding distinctions. These are used by sales forces to encourage prescribing doctors to shift from the original branded medicine to the evergreened branded medicine, reinforcing any existing brand loyalty while developing new loyalty in the evergreened brand and extracting a price premium beyond the original patent period. For virtually identical patented drugs, PBS data allow the identification of "prescribing shifts." Drug companies have large marketing budgets and use these to "educate" decision-makers in the prescribing process. Consequent prescribing shifts, between closely similar medicines with very similar patienthealth outcomes, indicate the returns to these marketing outlays.

There are substantial challenges in using official patent databases to identify secondary patents. These are discussed as background to the case selection for this study. 


\section{Patents and trademarks: empirical evidence on 'evergreening' from Australia}

\section{Setting the scene}

In 1958 Machlup advised the US Senate that a narrow definition should be taken to the term "patent abuse". In Machlup's view patent abuses occur only when strategies are employed to undermine the social objectives of the patent system by extending "monopolistic control ... in time, in scope, or in strength" (Machlup 1958: 10). Among a small list of patent abuses he identified "successive patenting of strategic improvements of the invention which make the unimproved invention commercially unusable after expiration of the original patent" and "creation of a monopolistic market position based on the goodwill of a trademark associated with the patented product or process, where the mark and the consumer loyalty continue after expiration of the patent" (Machlup 1958: 10-11). Thus the two issues considered in this paper - evergreening and the combination of patents and trademarks - are among Machlup's narrow list of patent abuses.

\section{Patents and evergreening}

Where large lumpy investments are combined with a relatively fast ability to imitate an invention, the market for invention may fail and useful new inventions will not attract the requisite investment. This perspective on the rationale for patents particularly characterises the pharmaceutical industry. Given that the cost of Phase III clinical trials generally falls on pharmaceutical firms there is a strong argument for providing a period of market monopoly for new active pharmaceutical ingredients (APIs) ${ }^{1}$ through the patent system.

Efficient and effective patent policy is that which most closely approximates to two conditions: (i) patents are granted only for inventions which would not otherwise occur; and

(ii) patents are granted only where the social benefits (private plus spillover benefits) exceed the social cost of the monopoly grant.

Although there are differing views on the cost of Phase III clinical trials, ${ }^{2}$ where these are high and the outcome is an API offering a real improvement in patient-health outcomes over existing and related medicines, the invention meets both conditions and the grant of a patent is relatively non-controversial. However, where the invention is a modification of the original API, the argument in support of patent grant is considerably weakened. Neither of the conditions for efficient patent grant are necessarily met - the impediment to invention can be low and the benefits far smaller.

Evergreening is defined as further patenting by the originator company of variations on the original API. Patenting of variations on the original API by entities other than the originator

\footnotetext{
${ }^{1}$ Some researchers use the term new chemical entities (NCEs) rather than active pharmaceutical ingredients (APIs). We prefer the latter as the former begs the question of how new is new.

${ }^{2}$ Light and Warburton (2011) analyse the industry claim that it takes US\$1.32 billion "to bring a new drug to market". They find that such this industry estimate is based on a 1983-94 biased sample of the most expensive cases. They point out that audited data provided to the US Internal Revenue Service for a similar period suggest that the average R\&D cost per new drug developed is closer to US\$22.5 million.
} 
company is referred to as secondary patents - that is we reserve the term evergreening for secondary patents which are taken out by the original owner.

A related issue is "me-too" drugs. ${ }^{3}$ These are drugs developed by competitors in response to the development of a block-buster API by an originating firm. The motivation is to obtain a share of a large and lucrative market. The company developing the me-too drug is looking for similar therapeutic effect, but with some variation in the chemistry, dosage, administration, formulation or method of treatment so that the "new" drug meets the very low inventiveness threshold for a patent grant. On some occasions these variations on the original theme may be more efficacious and/or more efficient, such as decreases in sideeffects. In others they offer no advantages. In developed countries the usual requirement for marketing approval is safety and efficacy compared to a placebo, not compared to other similar drugs already on the market (Holovac 2004; Murti et al. 2008; Goldacre 2012).

Whether such evergreening "inventions" involve the kinds of benefits to society that merit a patent grant is a matter for empirical assessment. The cases presented in this paper provide further data on the nature of the "improvements" claimed in evergreening patents and on the effectiveness - or otherwise - of such patents in delaying generic entry.

Global pharmaceutical companies spend a higher proportion of revenue on marketing than on R\&D. Data for 2000-07 indicate that the average spend on marketing and promotion is 23 per cent of turnover compared to 17 per cent on R\&D (European Commission 2009: 7-8). This is where trademarks become important - pharmaceutical products are best known by their trademark names not their chemical names.

\section{Using trade marks to establish brand loyalty}

The TRIPS treaty is ambiguous on trademarks. In Article 15 it first defines trademarks as signs "capable of distinguishing the goods or services of one undertaking from those of other undertakings" - that is the focus of the trademark is on company identity, not the specific product. This is consistent with the original purpose of trademarks - to associate producers with their products so that consumers could both select their desired price/quality range and could take action in case of defective products.

TRIPS also requires that "the nature of the goods or services to which a trademark is to be applied shall in no case form an obstacle to registration of the trademark". Article 20 requires that trademark use "not be unjustifiably encumbered by special requirements". An economist's reading of these clauses suggests that TRIPS confers no right to register trademarks for every different product produced by a company. Equally it suggests strong limitations on the extent to which governments can restrict trademarks for companies even if their products cause severe harm, such as death or disease.

The current WTO dispute over plain packaging of tobacco products is of considerable relevance to the issue of using trademarks for specific pharmaceutical products to extend consumer loyalty into the out-of-patent period. The cases investigated here throw some light on aspects of how trademarks are strategically combined with patents. Different

\footnotetext{
${ }^{3}$ While it is important to distinguish between secondary pharmaceutical "inventions" and me-too drugs, the patenting of me-too drugs is beyond the scope of this paper. It does however raise interesting issues about the impact of such patents on price - do they substantially reduce the price of treatment during the originator patent period? Is this price reduction (together with any genuine advances in safety or efficacy) sufficient to offset the social costs of resources used to find out how to do marginally differently what we already know how to do perfectly well (as Machlup noted in 1957)?
} 
trademarks for the same product can inhibit parallel importing - for example EFEXOR (Australia and Europe) and EFFEXOR (USA) - and the potential confusion caused by different product trademarks can be used to persuade courts to grant injunctions over generic entry.

This paper proceeds by reviewing the available literature on secondary patenting, with a focus on the empirical literature. Then section 3 of the paper considers the issues arising in attempting to identify relevant patents, before going on to describe the dataset used for analysis in this paper. The detailed case studies are presented in section 4 . The case study material adds considerable depth to the existing empirical literature on secondary patenting as, with one exception, that literature focuses on macro-level analyses. Macro-level analysis is substantially enhanced when it is based on a sound understanding of micro-level actions, so we believe this paper makes a useful contribution to further larger-scale analyses. The issues identified in the cases, particular the policy issues, are summarised in section 5 and discussed in comparison to some overseas approaches, such as India's specific exclusion from patentability of chemical variants which do not provide improved health outcomes, are made. There are clear implications from these cases for negotiation of intellectual property chapters in treaties such as the proposed Trans Pacific Partnership Agreement (TPPA).

\section{What we already know}

This strategy of taking out many secondary patents is referred to within the industry as "lifecycle management". Some of the literature on lifecycle management simply discusses strategies, including what kinds of secondary patents will survive legal challenges in which countries. ${ }^{4}$ This literature notes the value to brand pharmaceutical companies of patent litigation even on very weak (uninventive) patents as the returns achieved from an additional period without generic competition while the matter is before the courts will "easily outweigh the costs of patent litigation" (Burdon and Sloper 2003: 238).

A small empirical literature on these secondary patents has recently emerging, largely in respect of the USA. In an analysis of patents on new molecular entities listed on the US "Orange Book", 5 Kapczynski and colleagues distinguished between molecules with and without secondary patents. They found that secondary claims were common and that they added, on average, 6.5 years to patent life. Patents filed late during the life of the original compound (or API) patent were more common for higher sales drugs (Kapczynski et al. 2012). In the USA there are strong financial incentives for generic companies to challenge weak secondary patents so we might expect Australia to experience longer extensions to patent life through such secondary patenting. ${ }^{6}$

Amin and Kesselheim comment on the lack of rigorous analysis of secondary pharmaceutical patenting before presenting their results tracing secondary patents for two HIV drugs -

\footnotetext{
${ }^{4}$ See for example Burdon and Sloper 2003; Furrow 2008; Kvesic 2008.

${ }^{5}$ The Food and Drug Administration publication, Approved Drug Products with Therapeutic Equivalence Evaluations, is colloquially known as the Orange Book. It lists approved prescription drug products, their therapeutic equivalence evaluations, trade (brand) names, owners and patent and data exclusivity information. ${ }^{6}$ The Hatch-Waxman Act was a response to a CAFC decision that generic companies could not use patent data to prepare for market entry until the patent had expired - effectively extending the period of market exclusivity for brand medicines. The Act introduced data exclusivity as a new form of regulated restraint of trade and balanced this by providing a substantial incentive for generic companies to challenge patents that delay their market entry. The reward for a challenge which results in first generic market entry is a 180 day period of market exclusivity in this very large market (Holovac 2004). Only after this six month period are other generic brands permitted to enter the market. This is a substantial incentive to encourage companies to undertake the risks and uncertainty of patent litigation.
} 
ritonavir and lopinavir. Their basic search used a commercial patent database rather than the official USPTO databases. They supplemented this with searches of the Orange Book and other sources to identify 82 granted patents and 26 applications covering the two drugs or their combination. These patents or applications involved categories of compositions/formulations, processes, treatment methods and/or general patents. They found 28 patents/applications which "did not specifically mention either lopinavir or ritonavir but that could still serve as roadblocks to generic competition" (Amin and Kesselheim 2012: 2289).

Ouellette, considering patent data from the Orange Book finds the average number of patents per drug increased over time, from 2.5 in the late 1980s to nearly 3.5 in 2005, a statistically significant increase (Ouellette 2010: 316). She finds that the mean number of patents per drug is higher where there was priority FDA approval or a term extension. It was highest for "block-buster" drugs - over 5 patents/drug in the 2002-04 period. She also finds considerable variation between therapeutic groups in the mean number of patents per drug.

Hemphill and Sampat (2012) principally investigate the impact of patent challenges on the market life of APIs. Using data on 119 incidents of generic entry into the US market in the period 2011-10 they find that most patent challenges involve evergreening patents. The strongest predictors of patent challenges are a longer patent term and the presence of evergreening patents (themselves correlated), which suggests that challenges are a response to evergreening. The average number of patents per API is 2.7, with a median of 2 indicating a somewhat skewed distribution.

In contrast, in Canada, Bouchard et al. (2010) found a mean of 40 patents per drug. Using Canada's linkage register (similar in concept to the US Orange Book) Bouchard and colleagues investigate the linkage between drug patenting and drug approval for high-value drugs. In particular they investigate how aspects of regulatory design are linked to patenting and patent listing patterns. Using a database of 3,850 patents for 95 drugs, they found that on average only 5 per cent of the patents associated with each drug were actually on the linkage register. These are strategically selected. Bouchard had earlier shown that the empirical effect of the linkage regulations on the average patent term "amounts to an increase of 22 years, representing a doubling of the duration of patent protection beyond that associated with the originating patent" (Bouchard et al. 2009: 1499).

For Europe, of course, the recent Commission enquiry has pointed to the prevalence of evergreening patenting in Europe. The report notes the large number of patent applications filed around any single API and that the average number of patents per API was greater for the highest volume drugs (European Commission 2009: 10-11). For top-selling medicines the average number of patents and patent applications was 237, compared to 98 for medicines in general. If such secondary patents delay the entry of generic drugs beyond the term agreed in the patent bargain, this is a matter of substantial policy concern.

Christie and colleagues usefully review the literature estimating the number of patents held per API (2.7 to 41 ) before presenting data on the number, type and ownership of patents associated with 15 of the drugs with the highest outlays in Australia in the period 1990-2000 (Christie et al. 2013: 4). They note that previous studies have all focused on evergreening patents - that is on secondary patenting by the originator of the API. In contrast to earlier studies, Christie and colleagues look at all secondary patents relating to the 15 high value drugs, rather than those owned only by the originator company. They find, on average, 49 patents per API of which about 25 per cent are held by the originator company. 
In the very much smaller Australian market there is no government incentive for patent challenges. This contrasts with the US system, where a generic company successfully challenging a patent is rewarded with a 6 month period of market exclusivity. ${ }^{7}$ Because of the much smaller size of the Australian market such an incentive would have little impact, though alternative rewards could be developed. ${ }^{8}$ As the company challenging the patent bears all the risks and uncertainty but shares the reward (market entry) with all other generic companies, there is only a limited incentive to challenge even a very weak-seeming patent. We would therefore expect the number of evergreening patents to be larger than in the USA. A second factor contributing to an expected larger quantum of evergreening in Australia is the relative low inventive step in the Australian patent system (IP Australia 2009). From the data presented by Christie et al (2013) the estimated mean number of evergreening patents per API in Australia is 12, higher than that found in the USA, but low compared to the Canadian situation.

Christie and colleagues find that secondary patents on APIs are taken out by competitor companies, generic pharmaceutical companies and a range of non-profit organisations. They categorise these patents by whether they are alternate forms of the API; combinations with another API, changes to delivery mechanisms or formulations, processes for manufacture, methods of treatment (sub-divided into the original anatomical therapeutic class or a different class) and a residual category of miscellaneous patents. But the presentation of the data does not allow clear identification of, for example, whether non-originator brandfocussed companies are patenting "me-too" drugs or other types of variations.

\section{Methodology}

This section discusses two issues. First there is the challenge of finding a comprehensive listing of evergreening patents. Second there are the variety of sources we draw on to assess the impact of these patents and their cost.

\section{Finding related pharmaceutical patents}

Identifying all the patents relating to a single pharmaceutical compound (API) is not a simple matter. The case of venlafaxine and its major metabolite desvenlafaxine is taken as an example to describe the issues we encountered in extracting data on secondary patents. Venlafaxine is an international non-proprietary name (INN). Such names are designed to facilitate identifying specific pharmaceutical products.

An initial search for the word venlafaxine in the patent abstract identified 53 patent applications. As this did not include the original patent for the API, a further search was made for patents with venlafaxine in the title. This identified 47 patents, 28 of which had also been located through the abstract search. Overall 72 patent applications were identified in this way. From an independent search conducted by an experienced patent attorney, we had access to the title of the original API patent, filed in 1983. This original application was titled "phenethylamine derivatives" and neither the abstract nor the body of the specification contained the word venlafaxine. The newly invented compounds were simply referred to by letter. A further search was then undertaken for patents with the word phenethylamine in the title. This identified 13 patents, only one of which had been identified earlier (through the abstract/title search). Overall these searches identified all but three of

\footnotetext{
${ }^{7}$ This is available only to the first generic entrant (Holovac 2004).

${ }^{8}$ For example, a share of the taxpayer savings achieved through earlier generic entry.
} 
the originator company patents identified by the expert searcher. The fact that three key patents were missing from the structured searches, and that independent information was needed to locate the original API patent confirms that patent databases are not good sources of data for particular technologies. ${ }^{9}$

Our initial intention was to investigate a set of drugs identified on the basis of total Australian outlays in the 2011-12 financial year, ${ }^{10}$ specifically the 21 drugs with expenditure greater than $\$ A 80$ million. We also had available to us a set of 15 cases where the full set of evergreening patents had been identified by an experienced patent attorney. Given the challenges found in identifying relevant patents, this dataset was used as a cross-check as to whether a systematic approach to searching for patents was sufficiently reliable. There were 5 cases in common (Table 1 ).

Table 1 Structured compared to expert searches for evergreening patents

\begin{tabular}{|c|c|c|c|c|c|}
\hline & \multirow{2}{*}{$\begin{array}{l}\text { INN search - } \\
\text { \# patents } \\
\text { identified }\end{array}$} & \multicolumn{2}{|c|}{ Patents missing } & \multicolumn{2}{|c|}{ \# applications from originator } \\
\hline & & $\begin{array}{l}\text { Originator } \\
\text { patents }\end{array}$ & $\begin{array}{l}\text { Original NCE } \\
\text { patent }\end{array}$ & Total & $\begin{array}{l}\text { Missed in } \\
\text { structured search }\end{array}$ \\
\hline Atorvastatin & 119 & 2 & yes & 39 & 2 \\
\hline Clopidogrel & 47 & 11 & yes & 18 & 11 \\
\hline Olanzapine & 50 & 8 & yes & 27 & 8 \\
\hline Rosuvastatin & 35 & 12 & yes & 22 & 12 \\
\hline $\begin{array}{l}\text { Venlafaxine (+ } \\
\text { desvenlafaxine) }\end{array}$ & 68 & 3 & (yes)* & 26 & 3 \\
\hline
\end{tabular}

* The title of the original venlafaxine API patent was obtained from the expert search and was then used to identify additional relevant patents.

These data indicate that in all cases the key API patent would have been missed in searches based on the INN of the pharmaceutical. ${ }^{11}$ In two of the five cases more than half of the applications by the originator company would have been missed and in a third case almost a third. These concerns led us to the view that data from searches involving an expert were more reliable and would be used in this study. While this does not allow us the representativeness that would be ideal, it does allow us to explore the value of this case study approach. If the results are promising, we can seek research funds to hire experts to undertaken the search for a more representative set of pharmaceuticals.

Eleven of the 15 cases where data from the expert search were available involved litigation over evergreening patents. Such cases represent those where generic companies judge secondary patents to be particularly weak and thus worth the expense and risk of litigation. As a result more data are available to the researcher, particularly concerning the effectiveness of evergreening patents on delaying market entry. Summary data for the 15

\footnotetext{
${ }^{9}$ This is concerning, given the dissemination role that the patent system is meant to play. Our search does confirm Christie's results - the originator company owns about 30 per cent of the 84 applications identified.

${ }^{10}$ Australian financial years run from 1 July to 30 June. The year from 1 July 2011 to 30 June 2012 would be referred to either as FY 2011-12 or FY 2012.

${ }^{11}$ In the earlier Australian study a commercial reference volume (O'Neil 2010) was used to identify the original API compound patent as filed at the USPTO and this was then tracked to the Australian equivalent using the EPO's INPADOC database (Christie et al. 2013).
} 
cases are presented in Table 2. Surprisingly, in three cases the original API patent was never filed in Australia - all patents for alendronate, rosuvastatin and nevirapine are evergreening patents. In all but one case (rosuvastatin) the original compound (or first filed evergreening) patent has expired. The number of evergreening patents ranges from just six for nevirapine to a massive 51 for alendronate. From the viewpoint of generic entry, however, it is not just the volume of evergreening patents that is important (though this substantially increases the cost of assessing market entry). The nature of the evergreening patents is also critical.

\section{Data sources and background information}

Evergreening patents take many forms including, but not limited to, claims over variants to the original API, the processes of their synthesis, their use in pharmaceutical products in the treatment of specific diseases and illnesses, processes for the synthesis of intermediate components used in processes to synthesise APIs, processes removing impurities from APIs, and different methods of delivery, including the timing of delivery and the specific form (e.g. tablet or capsule). A particular issue is standard molecular variations of patented APIs, such as enantiomers, metabolites and salts.

Data used to investigate the evergreening patents in each case include the bibliographic information for each patent and information from the patent specifications. Where there has been litigation the court decisions provide insights both as to the content of the patent and the specific policy rules (legal doctrines) which affect the grant of evergreening patents. In some cases data and analysis are available from secondary sources - other academic or commercial discussion of the patents of interest.

A particular focus of each case is identifying the likely economic impact. Data on the number of prescriptions through Australia's Pharmaceutical Benefits Scheme (PBS), ${ }^{12}$ combined with price data allow a clearer estimate of the cost of patenting than is usual. Under the PBS there is a fixed maximum price paid by consumers and the difference between this and the agreed dispensed price is paid for by the Australian government (taxpayer). Once a generic product enters the market the price falls, initially by a statutory 16 per cent. Further price falls are linked to reported actual prices, but with an 18 month delay. ${ }^{13}$ Although PBS price data include a dispensing fee, this is offset by the price being the agreed rather than the actual price. The latter element may well exceed the former. Estimates of the cost of delayed generic market entry from PBS data thus provide only approximate estimates of taxpayer losses. We have no data to estimate the loss to generic companies from delayed entry.

\footnotetext{
${ }^{12}$ In Australia a drug which cannot gain listing on the PBS is likely to have a very limited market (though delisted drugs will have built up loyalty both among prescribers and final users). Effectively with the PBS the Australian government acts as a monopsony buyer, negotiating prices with supplying companies. The situation is complicated by the role (and political power) of pharmacists and PBS prices paid include various dispensing fees for pharmacists.

${ }^{13}$ This period has recently been reduced to 12 months (http://www.pbs.gov.au/info/industry/pricing/eapd; http://www.pbs.gov.au/info/industry/pricing/eapd/factsheet1-eapd-cycles).
} 
Table 2

The set of $\mathbf{1 5}$ cases - selected characteristics

\begin{tabular}{|c|c|c|c|c|c|c|c|c|c|c|}
\hline Drug & \multicolumn{2}{|c|}{$\begin{array}{l}\text { Original API patent } \\
\text { [first secondary patent] }\end{array}$} & \multirow{2}{*}{$\begin{array}{l}\text { last } \\
\text { patent } \\
\text { expiry }\end{array}$} & \multirow[t]{2}{*}{$\begin{array}{c}\text { Owner } \\
\text { (original patenter) }\end{array}$} & \multirow{2}{*}{$\begin{array}{c}\# \\
\text { secondary } \\
\text { grants }\end{array}$} & \multirow{2}{*}{$\begin{array}{c}\text { Currently } \\
\text { active } \\
\text { patents }\end{array}$} & \multirow[t]{2}{*}{ Litigation? } & \multirow[t]{2}{*}{$\begin{array}{l}\text { Patents } \\
\text { revoked? }\end{array}$} & \multirow[t]{2}{*}{ Interesting features } & \multirow{2}{*}{$\begin{array}{r}\text { Cost FY } \\
2012 \# \\
\text { \$ m m }\end{array}$} \\
\hline INN & file date & expiry & & & & & & & & \\
\hline $\begin{array}{l}\text { Venlafaxine (+ } \\
\text { desvenlafaxine) }\end{array}$ & $6 / 12 / 83$ & $6 / 12 / 08$ & $18 / 8 / 23$ & Pfizer (Wyeth) & 7 & 5 & yes & yes & metabolite & 191.9 \\
\hline $\begin{array}{l}\text { Citalopram / } \\
\text { escitalopram* }\end{array}$ & $5 / 1 / 77$ & $5 / 1 / 93$ & $19 / 04 / 26$ & Lundbeck & 39 & 2-3\# & yes & Partial & $\begin{array}{l}\text { enantiomer; but patent } \\
\text { held valid }\end{array}$ & 59.2 \\
\hline Clopidogrel & $7 / 7 / 83$ & $7 / 7 / 03$ & $10 / 6 / 19$ & Sanofi-Aventis & 12 & 8 & yes, 2 & 2 & enantiomer & 154.0 \\
\hline $\begin{array}{l}\text { Omeprazole/ } \\
\text { esomeprazole }\end{array}$ & $11 / 4 / 79$ & $11 / 4 / 99$ & $7 / 5 / 27$ & Astra (Hässle) & 61 & 25 & yes & no & $\begin{array}{l}\text { enantiomer; } 8 \\
\text { marketed versions }\end{array}$ & 286.3 \\
\hline Atorvastatin & $18 / 5 / 87$ & $18 / 5 / 12$ & $1 / 6 / 24$ & Warner-Lambert & 14 & 1 & yes & 1 & + obvious combination & 731.7 \\
\hline \multirow[t]{2}{*}{ Alendronate } & \multicolumn{2}{|c|}{$\begin{array}{l}\text { Original API never } \\
\text { patented in Australia. }\end{array}$} & \multirow[t]{2}{*}{$4 / 12 / 26$} & \multirow[t]{2}{*}{ Merck } & \multirow[t]{2}{*}{51} & \multirow[t]{2}{*}{10} & \multirow[t]{2}{*}{ yes } & \multirow[t]{2}{*}{1} & \multirow[t]{2}{*}{$\begin{array}{l}\text { breadth of original } \\
\text { patent }\end{array}$} & \\
\hline & $8 / 6 / 90$ & $8 / 6 / 10$ & & & & & & & & \\
\hline Risedronate & $20 / 12 / 85$ & $20 / 12 / 10$ & $14 / 4 / 25$ & Warner-Chilcott & 10 & 7 & no & & 7 marketed versions & \\
\hline Cefuroxime & $6 / 4 / 79$ & $6 / 4 / 95$ & $21 / 11 / 22$ & Glaxo & 24 & 1 & no & & 4 term extensions & \\
\hline \multirow[t]{2}{*}{ Rosuvastatin } & \multicolumn{2}{|c|}{$\begin{array}{l}\text { Original API never } \\
\text { patented in Australia. }\end{array}$} & \multirow[t]{2}{*}{$30 / 11 / 27$} & \multirow[t]{2}{*}{ Astra Zeneca } & \multirow[t]{2}{*}{19} & \multirow[t]{2}{*}{17} & \multirow[t]{2}{*}{ yes, 2} & \multirow[t]{2}{*}{ nyd } & \multirow[t]{2}{*}{$\begin{array}{l}\text { US litigation; Australian } \\
\text { opposition }\end{array}$} & \multirow[t]{2}{*}{466.5} \\
\hline & $1 / 2 / 00$ & $1 / 1 / 20$ & & & & & & & & \\
\hline Lansoprazole & $7 / 8 / 85$ & $20 / 9 / 09$ & $20 / 12 / 25$ & Astra Zeneca & 12 & & no & -- & & \\
\hline Meloxicam & $10 / 10 / 88$ & $10 / 10 / 08$ & $12 / 9 / 26$ & $\begin{array}{l}\text { Boehringer } \\
\text { Ingelheim }\end{array}$ & 8 & 7 & no & -- & & \\
\hline Zoledronic acid & $20 / 11 / 87$ & $20 / 11 / 07$ & $17 / 9 / 24$ & Novartis & 10 & 5 & yes & nyd & & \\
\hline Faxofenadine & $29 / 1 / 80$ & $29 / 1 / 05$ & $16 / 10 / 26$ & Sanofi-Aventis & 16 & 16 & yes & partial & & \\
\hline \multirow[t]{2}{*}{ Nevirapine } & \multicolumn{2}{|c|}{$\begin{array}{l}\text { Original API never } \\
\text { patented in Australia }\end{array}$} & \multirow[t]{2}{*}{$4 / 6 / 28$} & \multirow[t]{2}{*}{$\begin{array}{l}\text { Boehringer } \\
\text { Ingelheim }\end{array}$} & \multirow[t]{2}{*}{6} & \multirow[t]{2}{*}{5} & no & & & \\
\hline & $18 / 10 / 91$ & $18 / 10 / 11$ & & & & & & & & \\
\hline Olanzapine & $4 / 4 / 91$ & $3 / 3 / 12$ & $5 / 7 / 22$ & Eli Lilly & 22 & 7 & yes & nyd & & \\
\hline
\end{tabular}

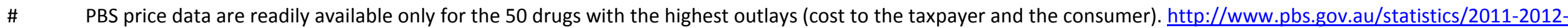
files/table-9b.pdf (5 October 2013) 
For each case we also focus on effective market life. Most patented products undergo a development and commercialisation process during the early years after patent filing. In all technology fields there is a delay - often substantial - between patent filing and entry of a product into the market. Pharmaceutical companies have successfully argued that these delays are particularly severe in the drug industry due to regulations designed to protect the public from unsafe or ineffective drugs. They have gained a global extension in patent term to 20 years through TRIPS. In Australia, as in a number of other countries, companies can apply for an extension in the patent term of up to five years if the regulatory approval process has taken five years or longer. The full patent term, usually measured from the filing date, can therefore be up to a maximum of 25 years. We measure the period of effective market exclusivity as the period between the first regulatory approval of the drug and the expiry of the relevant patent. This period is expected to be much shorter than 25 or even 20 years. Hemphill and Sampat measured effective market life using a different end-point - the approval of the first generic product. For the 119 drugs in their sample they found a range from 5.8 to 19.0 years with a mean of 12.15 (Hemphill and Sampat 2012: 330).

While we focus here on effective market exclusivity, it should be remembered that the originator company is able to prevent any other commercial development of the patented compound during the period prior to market approval. The pre-market period does, therefore, confer substantial commercial advantages despite the absence of any revenue flow. Importantly, it ensures that no other company has the opportunity to develop any health treatments based on the patented compound.

A final focus in each case is consideration of the evidence around the trademark and its use in marketing, including developing brand loyalty that extends beyond the patent protection period. Trademarks were identified from the Australian Therapeutic Goods Register, which also gave the approved date for market entry. They were cross checked with the official trademark register. PBS data provide volume measures for any listed drug from FY 1992-93. These data allow us to focus on "prescribing switches" where a closely similar replacement drug starts to become more heavily prescribed.

\section{The evergreening case studies}

The primary focus in the cases studies presented below is on the nature of secondary patenting and its impact on the timing of generic entry to the market. Brand names play an important role in drug evergreening. Where a variant of the original API (used in the original brand) is introduced the original brand will be cannibalised by the new brand (e.g. venlafaxine (EFEXOR) to desvenlafaxine (PRISTIQ)). Loyalty in the old brand (for which the relevant patents are about to expire) is thus transferred to the new brand (whose relevant patents won't expire for many years). The objective is to retain a patent-provided price premium over a much longer period. Typically such variants are enantiomers, metabolites, salts, esters or similar closely similar versions of the original API.

Alternatively the company introduces various "improvements" to the original drug. These include different synthesis processes, changes in the formulation of the drug, changes in the dosage regime, and changes in drug administration or in the method of treatment. The trade mark for such "improvement" drugs typically uses the original brand augmented by letters, such as 'XR' (extended release), or words, such as 'Plus' (implying a superior version of the original brand). An example of this kind of evergreening is venlafaxine (EFEXOR) to venlafaxine extended release (EFEXOR-XR) and FOSAMAX to FOSAMAX PLUS. Again, the objective is to retain a 
patent-provided price premium over a longer period, but by springboarding off the original brand rather than cannibalising it.

The first case - venlafaxine and its metabolite desvenlafaxine - has a number of interesting features. There are two patenting standards issues- patenting metabolites and patenting combinations of known things. It raises issues about the policies for efficient funding of access to medicines. And it provides an interesting insight into marketing and how heavy promotion of replacement brands is used to change prescribing patterns.

The next two cases concern the enantiomers of citalopram and clopidogrel. Citalopram and clopidogrel are each racemates - that is they each contain a carbon atom called a 'chiral centre'. ${ }^{14}$ A chiral centre is made up of two forms, called stereoisomers, isomers, or more specifically, enantiomers. These are mirror images of each other, in the same way as one's left and right hands are mirror images of each other. The racemate contains equal quantities of both enantiomers. The S-enantiomer rotates plane polarised light in a positive direction; the R-enantiomer rotates plane polarised light in a negative direction. The presence of 'chiral centres', enantiomers and racemic mixtures have been long understood. ${ }^{15}$ It has also been long understood that enantiomers behave differently biologically and that one enantiomer will usually be more pharmaceutically efficacious than the other, often with one enantiomer having all of the activity and the other enantiomer being inactive.

Both citalopram and clopidogrel were first patented in racemate form. Both were subsequently patented in enantiomer form. As was well known from pharma-chemistry, only one of the two respective enantiomers was patented. Both enantiomer patents were eventually challenged in the Federal Court - with contradictory results. In the initial judgements the citalopram enantiomer patent was upheld and the clopidogrel enantiomer patent partially upheld. On appeal, with decisions handed down about three months of each other and by the same three judges, the citalopram patent was upheld and the clopidogrel patent entirely invalidated.

These two appellate level decisions produced an inconsistent end result but only because in the citalopram appeal ${ }^{16}$ the patent was not challenged for lacking an inventive step, whereas in the clopidogrel appeal ${ }^{17}$ the patent was so challenged. ${ }^{18}$ There was, however, a deeper and more troubling inconsistency over the judicial approach to the issue of novelty. Novelty was contested in both appeals, however, only Justice Emmett invalidated both patents for want of novelty. In his opinion, the racemate patent necessarily disclosed both the enantiomers. Justices Bennett and Middleton took a narrower approach, finding instead that the racemate patent did not disclose the enantiomer in an isolated form which is, so they held, what the citalopram enantiomer patent claimed as the invention.

In September 2012, following a decision not to make legislative amendments to increase the height of the inventive step, IP Australia introduced changes to its Patent Manual of Practice \& Procedure to state that if an "isomer is prepared by routine separation techniques, the

\footnotetext{
${ }^{14}$ This discussion draws heavily on Alphapharm's public submission to the 2012-13 Pharmaceutical Patents Review, pp. 20-21 (copy available from authors).

${ }^{15}$ Louis Pasteur first deduced enantiomers in 1848.

${ }^{16}$ Alphapharm v Lundbeck [2009] FCAFC 70 (11 June 2009).

${ }^{17}$ Apotex v Sanofi-Aventis [2009] FCAFC 134 (29 September 2009)

${ }^{18}$ Lindgren J. had held in the citalopram case that there was an inventive step as it would not have been obvious to try to find the enantiomer - despite the fact that Lundbeck had done exactly that and that it was well known that one enantiomer is usually more effective than the other.
} 
single isomer will be an obvious solution. This is true even if it was not obvious beforehand which of the isomers would be more active."19

Against this rather murky legal background we discuss the evergreening patents surrounding citalopram and clopidogrel. The citalopram case also involves an extremely complex legal wrangle about a term extension on a patent. The clopidogrel case involves not only an enantiomer but also an obvious combination patent, adding to our knowledge about the effect of such patents. It also demonstrates how the strategic litigation game is used to delay loss of market exclusivity even where the supporting patent is so weak it is not worth the expense of defending.

There are two other enantiomer patents in our cases. The most globally famous case of enantiomer patenting is omeprazole and isomer esomeprazole - better known as LOSEC and NexIUM. In Australia there has been a recent legal challenge to the validity of the enantiomer patent and two related patents. ${ }^{20}$ This case also involves many different trademarks -8 versions were approved for market entry. LIPITOR (atorvastatin) is another extremely wellknown drug and also involves an enantiomer patent. Although this only extended market protection by five months it was successfully challenged and was revoked. ${ }^{21}$ Separately to this legal challenge, Ranbaxy challenged the validity of two US patents ${ }^{22}$ and the terms of the out-of-court global settlement ${ }^{23}$ in June 2008 provided Ranbaxy with the ability to enter the market ahead of its generic rivals in November 2011. ${ }^{24}$ Ranbaxy's strategy led directly to very disorderly generics entry to the market in Australia.

The next two cases involve drugs which treat osteoporosis. Alendronate is surrounded by an extraordinarily large number of evergreening patents -51 . Risedronate provides the same therapeutic treatment as alendronate and both are also marketed in combination with calcium carbonate and vitamin D. Risedronate has only 10 evergreening patents but, like es/omeprazole, has multiple marketed versions, perhaps throwing more light on the role of trademarks. The Pharmaceutical Benefits Advisory Committee (PBAC) has determined that "risedronate sodium and its combination formulations are interchangeable with alendronate sodium and its combination formulations on an individual patient basis in the treatment of osteoporosis and Paget Disease." ${ }^{25}$

The final case - cefuroxime, an antibiotic - is included because it managed to obtain not just one but four extensions to the normal patent term.

19 http://www.ipaustralia.gov.au/pdfs/patentsmanual/WebHelp/Patent Examiners Manual.htm (Section 2.5.4.1.3 on optical isomers) (7 October 2013).

${ }^{20}$ Ranbaxy v AstraZeneca [2013] FCA 368. Middleton J upheld the validity of the enantiomer patent on both inventive step and novelty grounds. He held the dosage form patent (695774) not infringed. The enantiomer patent is 676337 and the two related patents are 695774 and 695966.

${ }^{21}$ Ranbaxy $v$ Warner-Lambert [2006] FCA 1787; Ranbaxy $v$ Warner-Lambert [2008] FCAFC 82 (patent 628198).

22 US 4,681,893 and 5,273,995.

${ }^{23} \mathrm{http} / / /$ www.pfizer.be/sites/be/nl/media/press_bulletins/in_general/Pages/PfizerandRanbaxysettleLipitorpat entlitigationworldwide.aspx

${ }^{24}$ In the United States, Canada, Belgium, Netherlands, Germany, Sweden, Italy and Australia.

${ }^{25}$ PBAC, Public Summary Document in response to Sanofi-Aventis' request to reconsider the interchangeably of alendronate and risedronate, July 2010 PBAC Meeting, p.1 http://www.health.gov.au/internet/main/ publishing.nsf/Content/34AF82912B979571CA257BF0001FEAEE/\$FFile/Risedronate.pdf 


\section{A. Desvenlafaxine: patenting a metabolite}

Venlafaxine, a compound used in a medicine to treat depression, is metabolised into desvenlafaxine in the body. As such venlafaxine and desvenlafaxine have identical therapeutic effect. Desvenlafaxine has been assessed as offering no therapeutic advantage for any group. ${ }^{26}$ However, Wyeth, the owner of patents over venlafaxine and the medicines EFEXOR and EFEXOR-XR also applied for and was granted patents over desvenlafaxine and its use in a medicine to treat depression (PRISTIQ). Accordingly, it is useful to consider the eight patents together as a single group. Seven are evergreening patents. They cover processes to make venlafaxine, formulations, methods of treatment using venlafaxine, desvenlafaxine as a new API and the use of desvenlafaxine in medicines. Together, the total period of patent protection from these eight patents is nearly 40 years (Figure 1 ).

\section{Figure 1 Venlafaxine and desvenlafaxine patents}

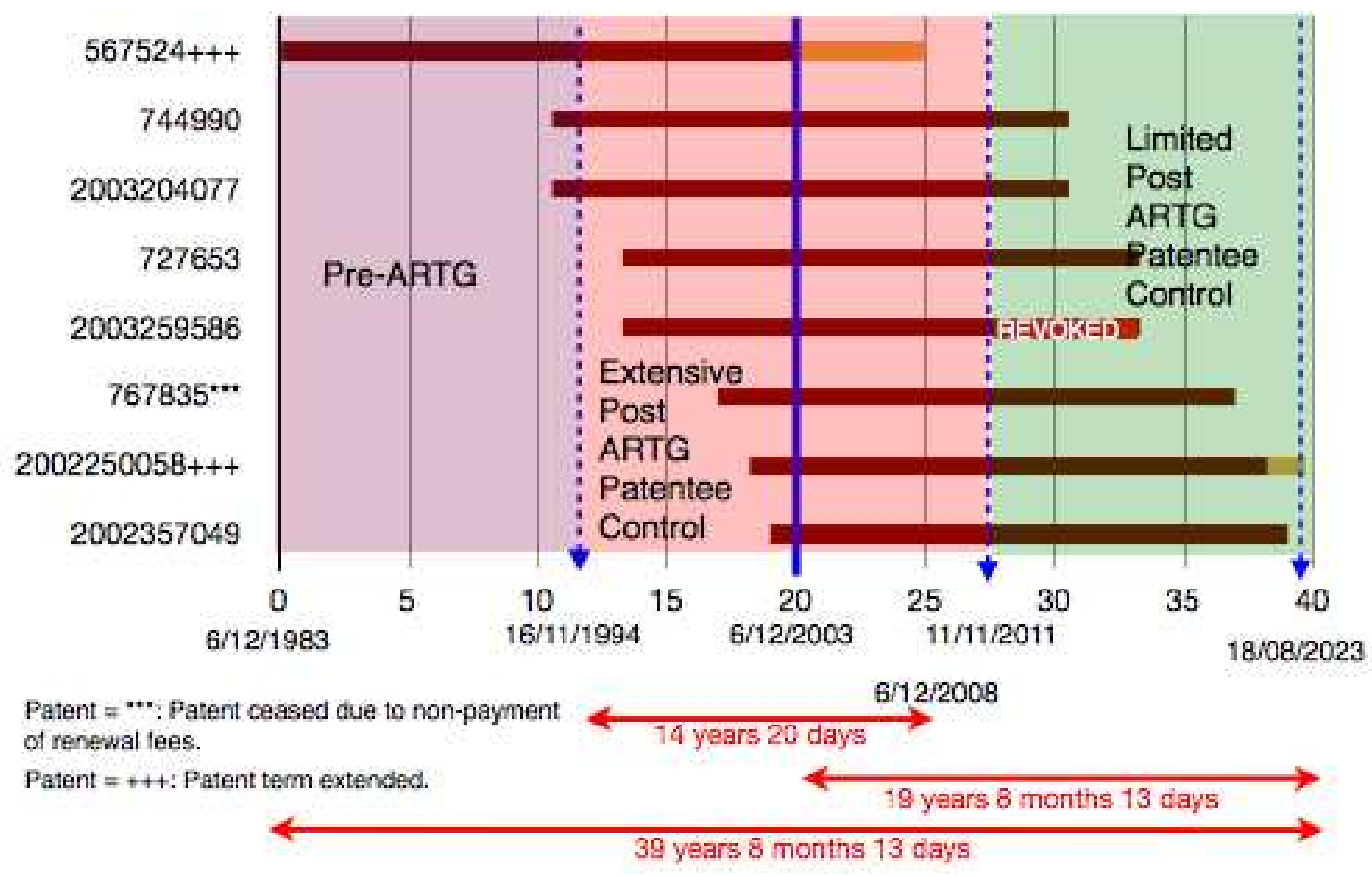

Source: Calculated from data extracted from AusPat and the ARTG.

\footnotetext{
${ }^{26}$ In Australia this assessment was made by Pharmaceutical Benefits Advisory Committee (PBAC), Public summary document: Desvenlafaxine succinate, July 2008, (www.health.gov.au/internet/main/ publishing.nsf/Content/pbac-psd-desvenlafaxine-nov08, accessed 16 April 2013) and expanded on in "Your questions to the PBAC: patent expiry and 'new' drug approval", Australian Prescriber, 32:3, June 2009, p.63.. NPS MedicineWise summarises the evidence on desvenlafaxine as "[ $t$ ]here is no evidence that desvenlafaxine is more effective, safer or better tolerated than venlafaxine or other antidepressants." http://www.nps.org.au/publications/health-professional/nps-radar/2009/march-2009/desvenlafaxine. Wyeth withdrew its application for marketing approval from the European Medicines Agency (EMA) as the EMA had found that "the benefits had not been sufficiently demonstrated and any benefits did not outweigh the identified risks" (Withdrawal Assessment Report for ElLEFORE: EMA/H/C/932: 22 January 2009, p.2 (at http://www.ema.europa.eu/docs/en_GB/document_library/Medicine_QA/2010/01/WC500064247.pdf). The data considered by the EMA were the results of nine studies, two of which included venlafaxine. The EMA notes that "the studies were not designed to compare the two medicines". Wyeth claims that PRISTIQ provides a superior health outcome over EFEXOR-XR which provides a superior health outcome over EFEXOR.
} 
The original compound (subsequently used in a medicine trademarked as EFEXOR) was first provided with patent protection by patent 1983022123 (567524) filed in December $1983 .{ }^{27}$ This patent was over a compound, subsequently named venlafaxine. ${ }^{28}$ It expired in December 2008, having been given a 5 year extension to the normal 20 year term. This initial patent prevented competitors from any use of the venlafaxine compound regardless of how it was made. The trademark EFEXOR was registered in January 1992 and the first regulatory approval of the medicine to enter the Australian market was on 16 November 1994. The original patent thus provided an effective market life for what became EFEXOR of just over 14 years - greater than the average for APIs of about 12 years found in the USA (Hemphill and Sampat 2012: 337).

So while Wyeth enjoyed market exclusivity over EFEXOR for over 14 years, ${ }^{29}$ it was also able to use its original patent monopoly over venlafaxine to prevent any alternative development of venlafaxine medicinal products for 25 years. The pharmaceutical sector focuses attention on the effective period of patent protection - the period after regulatory marketing approval of a medicine and before the compound patent expires. This focus downplays the full economic value of the compound patent to its owner. This distinction has been successfully used to argue for patent term extensions (of up to five years) -special assistance available only for pharmaceutical substances. Indeed, Wyeth's original venlafaxine compound patent was extended, from 20 years to 25 years.

Additional patent protection is provided by two treatment method patents, filed in 1994 . One is for use of venlafaxine for the "treatment or prevention of generalized anxiety disorder in mammals". The other is use for treatment of eight different medical conditions "in a mammal". These two treatment method patents run from 1994 to 2014.

In 1997 the owner, Wyeth, applied for a further EFEXOR patent, for an extended release (XR) version. Market approval for Australia was received in May 1998 and the extended release version was marketed as EFEXOR-XR. ${ }^{30}$ It rapidly became the prescribing norm. The first of these two XR patents is over "an extended release formulation of venlafaxine comprising a hard gelatine capsule containing a therapeutically effective amount of spheroids comprised of venlafaxine ...". ${ }^{31}$ Various forms of delivery mechanism (immediate, delayed or extendedrelease) have been well known since the 1960 s. $^{32}$

Wyeth later lodged a divisional from this first XR application and then a divisional of the divisional. The "grandchild", not filed until 2003, was granted a patent for "a method for providing a therapeutic blood plasma concentration of venlafaxine over a 24 hour period

\footnotetext{
${ }^{27}$ As the Australian Patent Office has ceased issuing separate numbers for granted patents, there is a problem in referring to granted patents. The only consistent approach is to use application numbers for all cases, whether they have a patent number or not. Application numbers are readily identified as the first four of the ten digits refer to the year in which the application was filed. But it is legally incorrect to refer to a granted patent with a patent number in this way. We have used both application and patent numbers (where these exist).

${ }^{28}$ At least one presumes the INN was not provided until after the patent was filed, as the patent specification did not refer to venlafaxine.

${ }^{29}$ Which would have been longer had a key evergreening patent not been revoked).

${ }^{30}$ Oddly, the trademark EFEXOR-XR was not registered until October 2003.

${ }^{31}$ Claim 1, application 1997016400 filed on 20 March 1997 and granted as patent 727653 on 5 April 2001.

${ }^{32}$ Bayer Pharma Aktiengesellschaft v Generic Health Pty Ltd (No 2) [2013] FCA 279 at 13.
} 
$\ldots . .{ }^{33}$ Because they were linked, both of these patents claim protection from 1997 and would have been expected to expire 2017.

The grandchild patent has, however, been largely revoked. The legal proceedings that led to the revocation of the EFEXOR-XR method of treatment patent commenced with the grant of an interim injunction in June 2009, some months after the expiry of the original EFEXOR patent. This injunction was not lifted until November 2011 when the principal claims of the patent were held to be invalid. The legal action delayed generic entry by some two and a half years.

The entry of generic companies after substantial revocation of the 2003259586 patent indicates that it was this patent, not its grandparent (application 1997016400, in force until 2017) that prevented the entry of generic versions of extended release venlafaxine. Competition was being restrained by the method of delivery aspects of the patent rather than the formulation aspects. Indeed it was the broadening of the patent claims, from a hard gelatine capsule which achieved extended delivery to claims for any method of extended delivery, which led to the patent being held invalid ${ }^{34}$ The timing of generic entry suggests that the two treatment method patents were not effective in blocking generic market entry.

During the period when generic market entry was delayed Wyeth (now Pfizer ${ }^{35}$ ) undertook substantial marketing for its replacement product, PRISTIQ (desvenlafaxine). ${ }^{36}$ Indeed Pfizer's marketing of desvenlafaxine in February 2009 was so lavish that it has attracted the attention of investigative journalists. ${ }^{37}$ As Figure 2 shows, almost as soon as PRISTIQ entered the market (in early 2009) there was a marked shift in prescribing away from EFEXOR-XR. By the time the injunction was lifted and generic venlafaxine was allowed on the market, Wyeth's replacement product, PRISTIQ, had achieved a 37\% market share.

Wyeth applied for three patents to protect PRISTIQ, one of which has since lapsed. The first patent, 2001017833 filed in late 2001, claimed ethers of O-desmethyl venlafaxine. Application 2002250058, filed in February 2002, claimed a novel succinate salt of Odesmethyl venlafaxine. Together these two patents provide PRISTIQ with protection from competition for the period 2002 to 2023.

The first of these patents, granted an 18 month term extension, covers desvenlafaxine and virtually any use that may be made of it as a medicine. The second covers a process of synthesis. It is unclear why 2001017833 passed the patent thresholds of novelty and inventiveness. It was well-known that venlafaxine metabolised into desvenlafaxine in the human body. How the patent office could then have considered desvenlafaxine novel is hard to understand. What was the economic rationale for granting this patent? The minor change in formulation provides an identical therapeutic effect. The difference in chemical composition provides little, if anything, in the way of new knowledge. So there is neither a health benefit nor a spillover benefit to offset the substantial costs of the patent grant.

\footnotetext{
${ }^{33}$ Application 2003259586, filed on 30 October 2003, but claiming a priority date of 20 March 1997 through its parent (lapsed application 2000065442) and grandparent (application 1997016400).

${ }^{34}$ Sigma Pharmaceuticals v Wyeth (No 3) [2011] FCAFC 165.

${ }^{35}$ Pfizer took over Wyeth with effect from October 2009 (http://en.wikipedia.org/wiki/Wyeth).

${ }^{36}$ The PRISTIQ trademark was registered in April 2005.

${ }^{37}$ Who point out that this "education" event stands out as the most expensive event in a database of 156,000 such events, see Clare Blumer, "Party like your drugs going generic", 31 May 2013, The Global Mail, (http://www.theglobalmail.org/feature/party-like-your-drugs-going-generic/624/).
} 
Figure 2 Prescribing shift: venlafaxine and desvenlafaxine

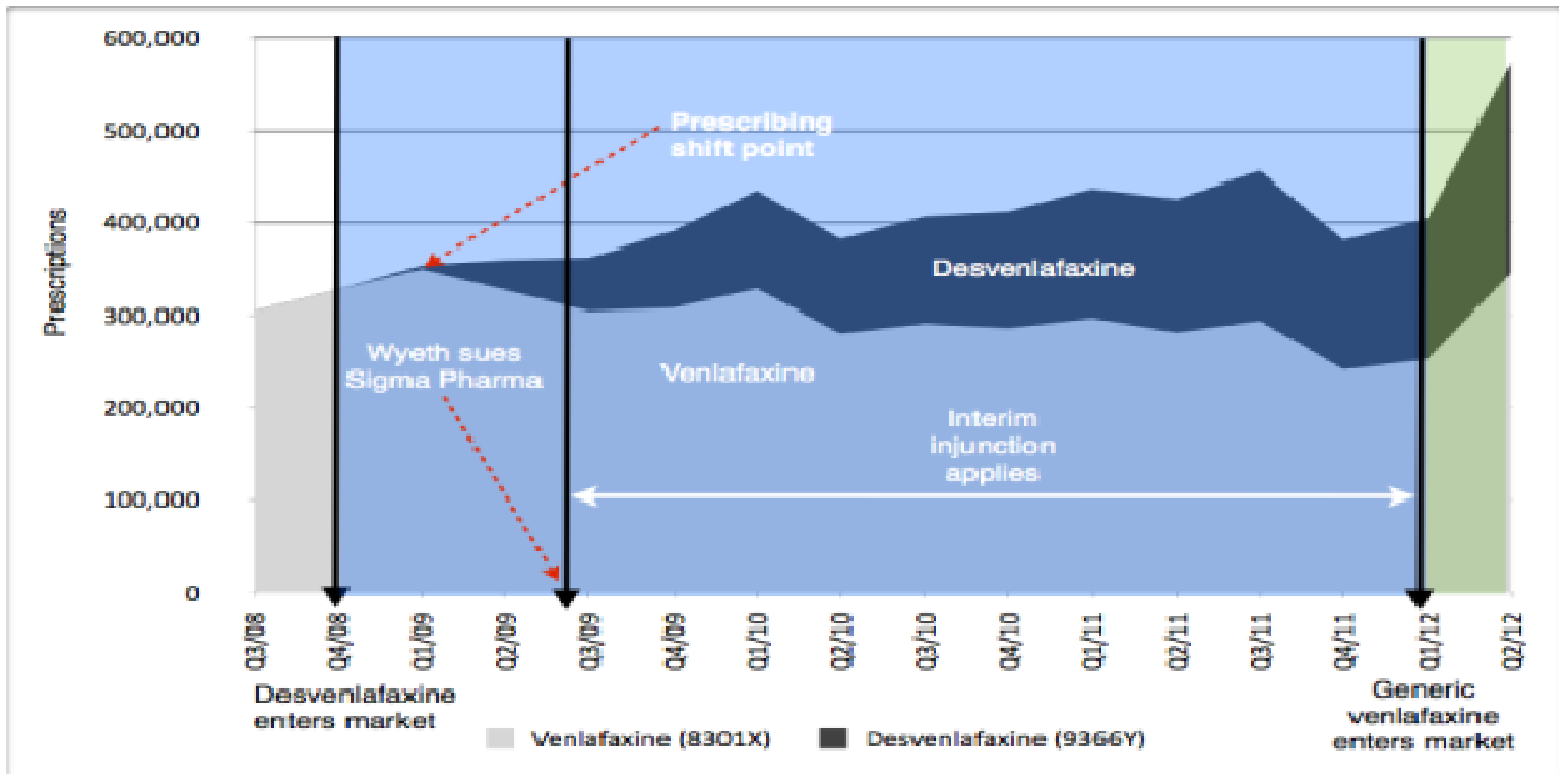

Source: Calculated from data from https://www.medicareaustralia.gov.au/statistics/pbs_item.shtml.

There are two elements to costing the consequences of this low standard of patenting in the des/venlafaxine case. Firstly there is the period when generic competition for EFEXOR-XR was delayed by litigation. Then there is the issue of the cost of the prescribing switch from EFEXOR-XR to PRISTIQ.

\section{Estimating the costs: delayed generic venlafaxine}

The injunction against Sigma was granted on 3 June $2009 .{ }^{38}$ The Full Federal Court found the claims in the patent which had restricted generic entry to be invalid on 21 December 2011 and lifted the injunction. ${ }^{39}$ But Pfizer appealed, and it was not until 11 May 2012 that the matter was finally settled when the High Court refused leave to appeal. These legal manoeuvres kept generics off the market for over two and a half years - in fact generic extended release venlafaxine first entered the market in early 2012, triggering a 16 per cent price fall for EFEXOR-XR on 1 April 2012. The cost to the Australian taxpayer of the delayed entry has been estimated as $\$ 209$ million. ${ }^{40}$

Once a generic product enters the Australian market there is an immediate 16 per cent fall in price. Prices continue to fall over time as actual prices paid by pharmacists are monitored and reported, though an initial 18 month delay (now 12 months) is built into this system. It is unclear why governments have considered that the taxpayer should fund higher hypothetical rather than lower actual prices. Typically competition between generic suppliers (as they negotiate contracts with different chains of pharmacies) means quite substantial actual price falls after generic entry.

\footnotetext{
${ }^{38}$ Sigma Pharmaceuticals v Wyeth [2009] FCA 595.

${ }^{39}$ Sigma Pharmaceuticals v Wyeth (No 3) [2011] FCAFC 165.

40 Alphapharm submission to the Pharmaceutical Patents Review. These submissions used to be publicly available at https://pharmapatentsreview.govspace.gov.au/submissions/. IP Australia took this website down during the caretaker period and has not yet re-established it. Please contact us for a copy.
} 


\section{Estimating the costs: grant of patent to desvenlafaxine}

In a comparison of the pharmacokinetics of desvenlafaxine and its parent drug, Sopko and colleagues conclude that it is "similar to its parent drug venlafaxine in efficacy, safety, and pharmacologic parameters" and then go on to suggest that the critical issue is likely to be cost as one was due to go off patent. Their final conclusion is that, because of this "the ultimate usefulness of desvenlafaxine in treatment of MDD [major depressive disorder] appears to be insignificant" (Sopko Jr et al. 2008: 1445).

What then is the cost of this insignificantly useful drug?

From generic entry until 1 April 2013 venlafaxine and desvenlafaxine were in separate PBS categories $^{41}$ and so were priced differently. In late 2012 the equivalent dose of desvenlafaxine was $\$ 50.52$ or $\$ 43.41$ compared to $\$ 44.20$ and $\$ 37.81$ for venlafaxine. As a consequence each time a GP prescribed desvenlafaxine the taxpayer paid either $\$ 6.32$ or $\$ 5.60$ more. This is a very high volume drug and the additional taxpayer impost was between \$A6.7 and \$A7.6 million a year. ${ }^{42}$ The underlying patents do not expire until August 2023. Action was taken to place the two products in the same PBS category, with effect from 1 April 2013. ${ }^{43}$ But by August 2013 the prices had still not equalised, though the differential had fallen to $\$ A 4.31$ or $\$ A 3.73$ depending on the dosage prescribed. ${ }^{44}$ During the 2012 financial year, the latest for which detailed usage data are available, 1,199,515 desvenlafaxine scripts were written (compared to 2,466,460 venlafaxine scripts). While it is pleasing that the desvenlafaxine share of the market has fallen back to 33 per cent, the additional annual impost on taxpayers from these prescriber decisions is still between \$A4.5 to $\$ A 5.2$ million. This represents a completely unjustified transfer from Australian taxpayers to Pfizer.

These costs estimates are limited to the additional taxpayer cost of Pfizer's business strategy. We do not have data on the costs incurred by the generics industry from being shut out of this segment of the market. Nor are there any data on the longer-term implications for the viability of Australia's generic pharmaceutical industry.

The fundamental question is what is the benefit to Australia for granting a patent for this metabolite when a 25 year patent had already been granted for its therapeutically equivalent parent, venlafaxine. The decision that the metabolite was patentable clearly indicates the very low current standard of inventiveness in the patent system. Australia is not the only country in which a patent has been granted for both venlafaxine and desvenlafaxine.

\footnotetext{
${ }^{41}$ The PBS has two categories (called "formularies"). Put simply, F1 contains all drugs where there is no generic version on the market. F2 contains all drugs with generic equivalents. All similar drugs are reimbursed at the same price, though a "brand premium" is allowed for the original product under limited circumstances.

${ }^{42}$ Depending on the balance between the different dosages of PRISTIQ. Calculated from data on volumes of prescriptions dispensed in FY 2012 (http://www.pbs.gov.au/statistics/2011-2012-files/table-9b.pdf) and data on dispensed PBS prices from http://www.pbs.gov.au/medicine/item/9366Y-9367B.

${ }^{43}$ With effect from 1 April 2013 desvenlafaxine was moved from the F1 to the F2 formulary (National Health (Listed drugs on F1 or F2) Amendment Determination 2013 (No. 2)). Venlafaxine and desvenlafaxine have now been co-located in a "derivative therapeutic group." This signals to prescribers that the two drugs are interchangeable but does not allow substitution at the dispensing level (see http://www.pbs.gov.au/info/publication/factsheets/venlafaxine-therapeutic-group).

${ }^{44}$ The August prices were $\$ A 48.62$ for $100 \mathrm{mg}$ of desvenlafaxine (PBS code 9367B) and \$A44.31 for venlafaxine (150mg, PBS code 8302Y) - a differential of $\$ A 4.32$ (down from $\$ A 6.12)$. For the lower dose, prices were $\$ A 41.65$ for desvenlafaxine 50mg (PBS code 9366Y) and $\$ A 37.92$ for $75 \mathrm{mg}$ venlafaxine (PBS code 8301X) - a differential of $\$ 3.73$ down from the $\$ A 5.60$ differential at the beginning of 2013 .
} 


\section{The role of trademarks}

In awarding an injunction to prevent Sigma from entering the market for extended release venlafaxine in June 2009, Sundberg J placed considerable weight on the evidence (from an expert for the patent owner) that "changes in the appearance of medication by different packaging or appearance can cause confusion in depressed patients, leading to problems with the regular taking of the medication, missed doses or discontinuance." This evidence was seen as being supported by Sigma's Chief Executive who "said that pharmacists are generally concerned that if patients are converted to a generic equivalent of a product, they should not be required to switch again, either back to the originator brand or to another generic". ${ }^{45}$ The judge concluded that it "is not in the public interest that vulnerable people, those with mental health issues, including depression, and elderly patients with a variety of medications, be subjected to confusion as a result of the refusal of interlocutory relief." 46

Thus while the judge found that there was a prima facie case that the disputed patent was invalid, he granted an injunction which delayed generic entry by nearly two and a half years. This decision was based on the balance of convenience relying on two factors: a view that it would be impossible to adequately recompense Wyeth for lost profits once generic entry had taken place; ${ }^{47}$ and the evidence about confusion among mentally ill and older patients. Not only did the EFEXOR-XR trademark provide the usual consumer loyalty, it was a key argument in ensuring that an invalid patent was allowed to delay generic entry to the market.

\section{Des/Venlafaxine: overall findings}

The data in this case raise the following issues:

- What is the basis for granting patents based on the type of drug release - immediate extended or delayed? Such delivery alternatives have been known since the 1960s. Combining them with a previously patented compound is the kind of combination that is clearly not inventive;

- What is the basis for granting a second patent (for a metabolite)? How, in the case of desvenlafaxine, was this able to pass the novelty test? What strange quirk is there in patent law that deems something already known to be "novel"?

- Trade marks clearly play an important role in maintaining and extending market position and market premiums. Is such a strategy for extending the market power for a patented drug consistent with the goals of innovation and health policy? and

- Why does PBS pricing policy allow different payments for therapeutically equivalent drugs? Why do these pricing policies require taxpayers to continue to pay prices that are higher than actual prices?

\footnotetext{
${ }^{45}$ Sigma Pharmaceuticals (Australia) Pty Ltd $v$ Wyeth [2009] FCA 595 at 63.

${ }^{46} \mathrm{Ibid}$ at 65.

${ }^{47}$ As the disputed patent was not due to expire until 20 March 2017, this meant nearly eight years of monopoly pricing would have been lost. While the mandated PBS price fall on generic entry is clear, there does not appear to be any mechanism to restore the price if the disputed patent is found to be valid and generics are removed from the market. There was no discussion in the judgement about the cost to the taxpayer over the delayed generic entry.
} 


\section{B. Patenting enantiomers: Citalopram / escitalopram}

This is the first of two cases where the patent on a pharmaceutically active enantiomer was challenged for validity, given the earlier patenting of the racemic compound. The antidepressant drug citalopram is the racemic mixture of its $\mathrm{S}$ - and R-enantiomers. The full biological effect of CIPRAMIL (citalopram) is due to the S-enantiomer. The patent for the racemic compound was granted in 1980, expiring in 1993 after 16 years (the then maximum patent term). CIPRAMIL was not approved for marketing in Australia until 1997. This would seem to suggest a complete lack of any exclusive period in the market. But this would ignore that Lundbeck had the sole right to commercial uses of citalopram, thus preventing competitors from developing this compound into any alternative competing medicine. There was in fact no competition of any kind to CIPRAMIL until Lundbeck introduced the enantiomer product LEXAPRO. ${ }^{48}$ CIPRAMIL and LEXAPRO are here treated together (as are all drugs with chiral centres and enantiomers) as the mechanism for therapeutic effect is identical.

A patent for escitalopram (the S-enantiomer of citalopram - marketed as LEXAPRO) was filed in 1989 and granted in 1992 with an expiry of 13 June 2009. LEXAPRO was approved for marketing in Australia in 2003. Counting effective market exclusivity as commencing on market approval for CIPRAMIL and ending when the enantiomer patent ceases, Lundbeck received $11 \frac{1}{2}$ years of market exclusivity for these closely related products. This is close to the US average of 12 years (Hemphill and Sampat 2012). Of course Lundbeck had exclusive commercial rights for much longer - from the filing of the original patent (5 January 1977).

Lundbeck owns 40 evergreening patents around citalopram (Figures 3 and 4) with a further 18 applications having lapsed or been withdrawn before grant. While the original API patent was filed in 1977, then next filing was not until 1985, when a patent for a process to prepare an intermediate product was filed. ${ }^{49}$ There was another gap before the patent for the Senantiomer compound was filed in 1989. Six method of production filings in 1988 and 1989

\section{Figure $3 \quad$ Lundbeck's citalopram and escitalopram patenting}

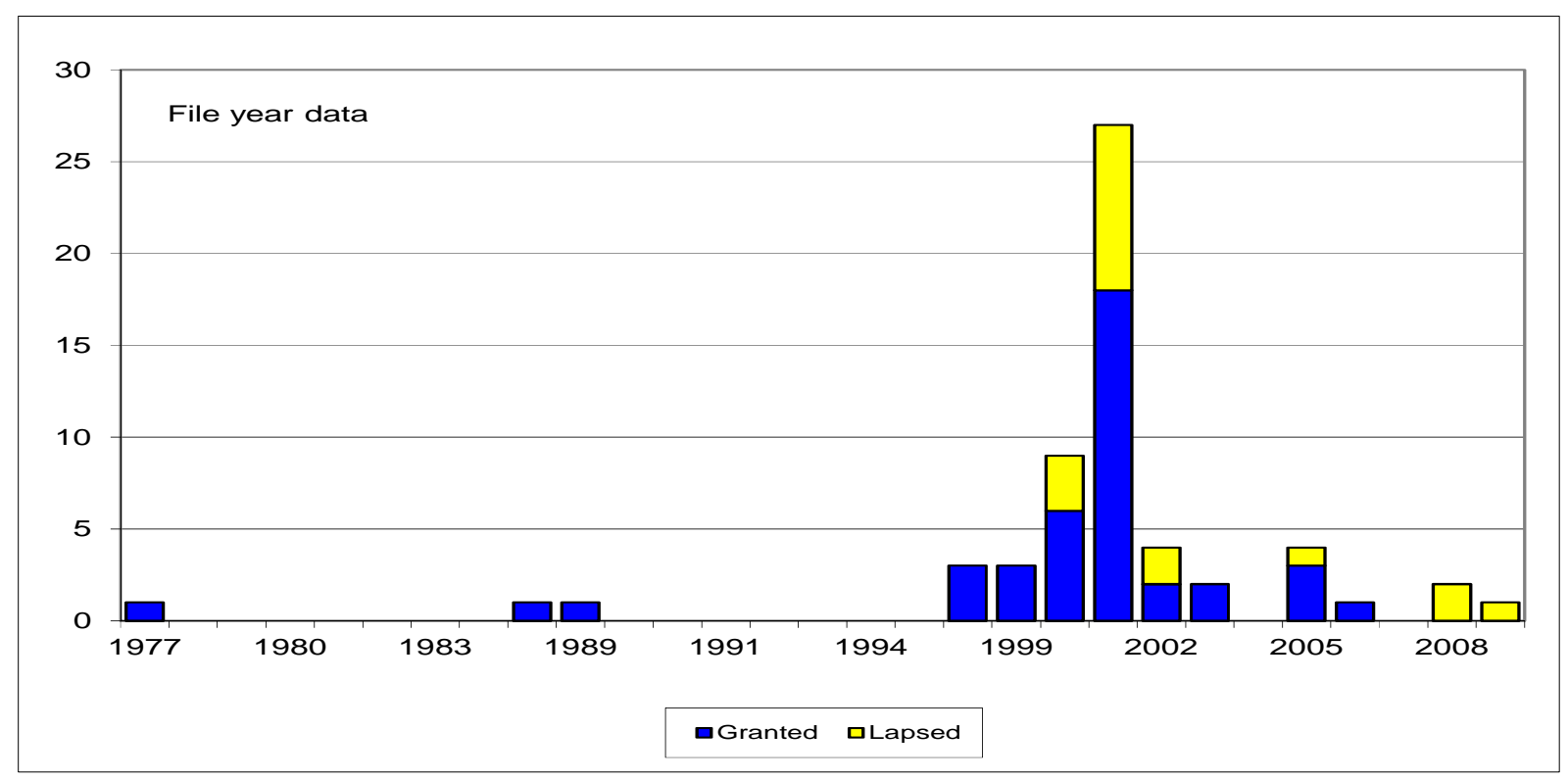

Source: Calculated from data from AusPat.

\footnotetext{
${ }^{48}$ As will become clear later, it was patent 623144 which prevented generic entry.

${ }^{49}$ Application 1985045776 also claimed the intermediate product.
} 
Figure 4 Citalopram and escitalopram

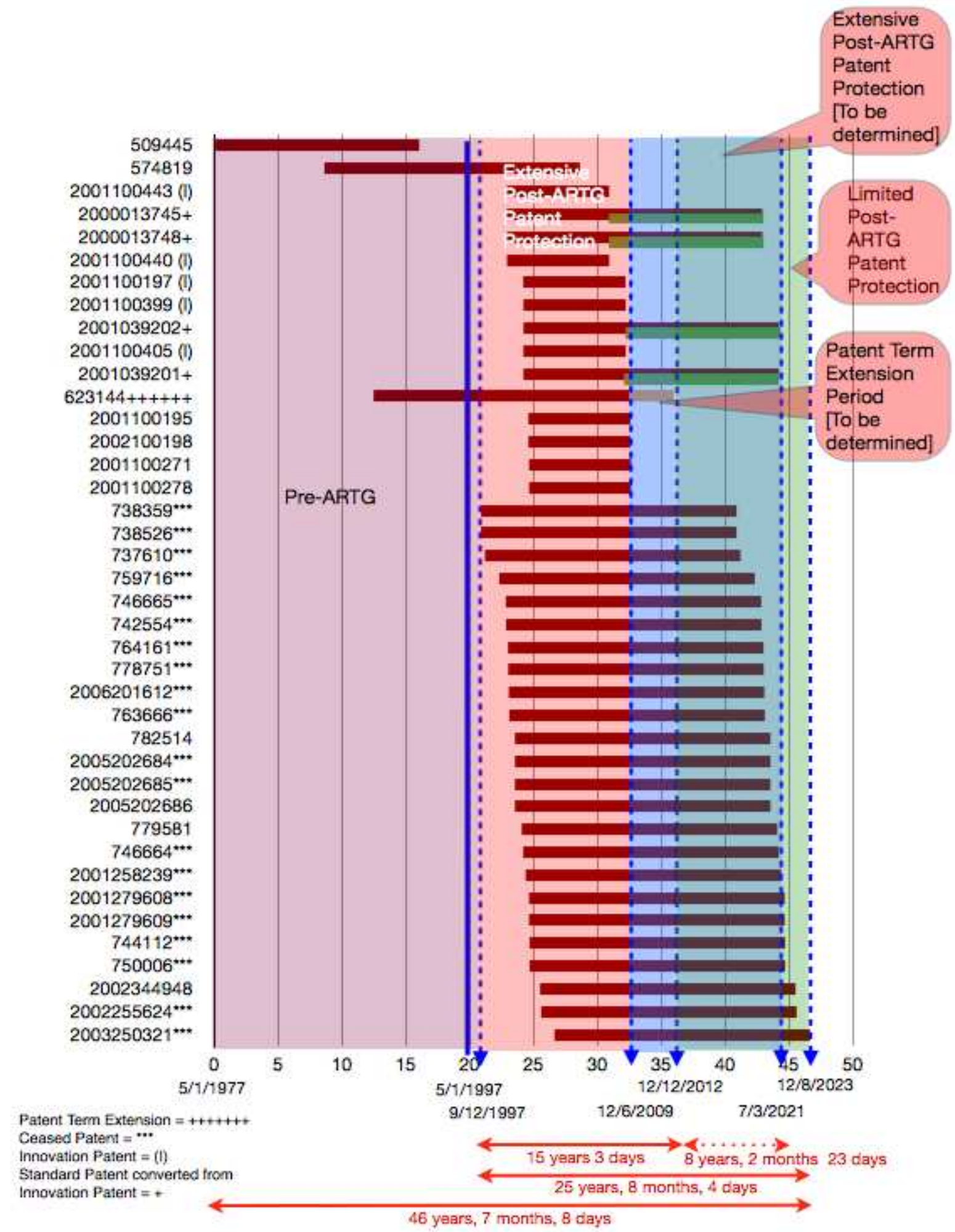

Source: Calculated from data extracted from AusPat and the ARTG.

were all granted. Peak patenting activity was in 2000 and 2001. Six 2000 applications were granted, 5 for production methods and one for a treatment method patent. In 200118 of 27 applications were granted. One was for a product but the remainder were all for production processes. One of these production process patents $(2001026798 ; 779581)$ was the subject of 
litigation and was revoked. ${ }^{50} \mathrm{~A}$ final eight patents have been granted from filings between 2002 and $2006-4$ for production processes, one for a product and three for treatment methods. Only three patents are currently in force - 2000058061, a treatment method, expires on 7 July 2020; 2002344948, a production process, expires on 25 June 2020; and 2005202686, another treatment method expires on 20 June 2025. There are however at least 25 evergreening patents with a "ceased" status, meaning that with the payment of back fees they could be revived and extend patent protection to 19 April 2026.

The second evergreening patent, the enantiomer, played a critical role in maintaining market exclusivity for Lundbeck through its LEXAPRO product for escitalopram. There is a complex legal battle around a 5-year patent term extension to 13 June 2014. With this term extension Lundbeck's effective period of market exclusivity increases from $11 \frac{1}{2}$ to over 16 years much longer than the average period of market exclusivity in the USA. The dispute has involved issues about validity and the patent term extension.

On appeal the Full Federal Court (FFC) upheld the validity of the patent but revoked the term extension. ${ }^{51}$ The FFC held that the patent for the S-enantiomer was novel - prior disclosure of the racemate did not destroy novelty in the enantiomer. The validity decision was based on an extremely narrow definition of novelty (with Justice Emmett dissenting). However the patent term extension was confirmed as invalid - the relevant reference point should be the initial racemic medicine not the enantiomer medicine.

The original validity decision on this evergreening patent is worth discussing in some detail as it shows the gulf between the economic objectives of a patent decision and the narrow semantic basis used to determine individual cases. Disregarding as irrelevant comments from the UK courts about the low inventive step in Australia, Justice Lindgren drew on the High Court's very narrow reading of obviousness in the Astra decision. ${ }^{52}$ Obvious to try is not the appropriate test of inventiveness - the appropriate test is whether an uninventive skilled person would be "led as a matter of routine to the desired result" with a reasonable expectation of success. ${ }^{53}$ The assessment was phrased in terms of whether it was obvious to try to obtain either enantiomer as a treatment for depression. ${ }^{54}$ The skilled addressee (the relevant judge) was determined to be "a [non-inventive] team of experienced medicinal chemists." ${ }^{55}$ It was agreed that this team would have recognised citalopram as a chiral molecule and that in 1988 techniques to obtain the individual enantiomers of racemates were part of common general knowledge. It was also accepted that it was part of the common general knowledge that one enantiomer might possess all of the pharmacological activity of the racemate. But it was not agreed that obtaining an individual enantiomer was an "obviously desirable result." ${ }^{156}$ Lindgren J concluded that because citalopram was safe and effective there was no "significant felt need or desire to obtain the enantiomers of citalopram" despite the fact that Lundbeck had done so. ${ }^{57}$ This was the critical factor in the

\footnotetext{
${ }^{50}$ We have been unable to find out any facts about this revocation - AusPat simply gives "revoked" as the reason for the revocation.

${ }^{51}$ H Lundbeck A/S v Alphapharm Pty Ltd [2009] FCAFC 70.

${ }^{52}$ Aktiebolaget Hässle v Alphapharm Pty Ltd (2002) 212 CLR 411 (Astra).

${ }^{53}$ Alphapharm Pty Ltd $v$ H Lundbeck A/S [2008] FCA 559 at 180.

54 Ibid, 189-191.

${ }^{55}$ Ibid at 202, with the non-inventive quality specified at 206. Quite how the patent world expects such a team to be non-inventive is unclear. The US Supreme Court considered this matter in 2007 and held that the ordinary person skilled in the art should be allowed normal inventiveness (KSR v. Teleflex 127 S.Ct. 1727 (2007).

${ }^{56}$ lbid at 394.

${ }^{57}$ Ibid at 421.
} 
decision to uphold the patent as inventive. This decision cost the Australian taxpayer an estimated \$A47-62 million.

The term extension litigation on the enantiomer patent remains on-going. The Full Federal Court held the patent term extension invalid ${ }^{58}$ just two days before expiry of the standard 20 year patent term (11 June 2009), however, Lundbeck immediately applied for a 10-year extension of time on the deadline for re-applying for a second patent term extension. The extension of time application was opposed by four generic companies but eventually granted by the Patent Office. ${ }^{59}$ Since then the generic companies have appealed to the Administrative Appeals Tribunal (AAT). ${ }^{60}$ The AAT did not reverse the Patent Office decision, and the generic companies then appealed to the Full Federal Court. As of the date of writing no decision has been handed down by the Full Federal Court. This litigation has preserved Lundbeck's ability to bring a second set of patent infringement proceedings against the generic companies that launched citalopram related medicines in December 2009 and to retrospectively seek to recover lost revenue caused by the market entry of their products.

Beyond this litigation are two innovation patents. An innovation patent, a uniquely Australian construct, has an eight year term and is simpler to obtain than a standard patent, having a lower standard of inventiveness - a so-called 'innovative step'. Innovation patents are identified in Figure 4 by the mark '(I)' appearing after the patent number. There are five innovation patents (all of which have expired). But two have been 'converted' into three standard patent applications, which may subsequently be granted. If granted, these will have a standard term of 20 years retrospectively reaching back to the filing date of the innovation patents. Generic companies thus face the prospect of yet another round of litigation. In a worst case scenario the potential period on which damages can be calculated may extend beyond the maximum possible patent term extension date (12 December 2012 depending on the outcome of the litigation discussed above). While their liability for patent infringement will depend on the breadth of these three converted patents, this strategy, available only in Australia, has provided Lundbeck with a duality of patent protection over the same compound and related medicines that have been patent protected since 1977.

Since an innovation patent provides the patent owner with precisely the same rights to damages and injunctions for infringement as does a standard patent, and since the time for grant is significantly abridged, the incentive to utilise this strategy is clear. Given the propensity of Australian courts to issue interim injunctions for pharmaceutical patent infringement, Lundbeck may well be able to delay generic entry as soon as these converted patents are granted.

Lundbeck has, of course marketed LEXAPRO heavily. The prescribing shift achieved by this marketing is shown in Figure 5. By the end of the 2013 financial year escitalopram had achieved a 63 per cent share of the total market of \$A632 million. ${ }^{61}$ Depending on the

\footnotetext{
58 Lundbeck v Alphapharm [2006] APO 18 (19 May 2006); Alphapharm v Lundbeck [2008] FCA 559 (24 April 2008).

${ }^{59}$ Alphapharm v Lundbeck [2011] APO 26 (1 June 2011).

${ }^{60}$ Re Aspen Pharma and Commissioner of Patents and Lundbeck (and others) [2012] AATA 851.

${ }^{61}$ Calculated from PBS benefit data at https://www.medicareaustralia.gov.au/statistics/pbs item.shtml using codes $8220 \mathrm{P}, 8702 \mathrm{~B}$ and $8703 \mathrm{C}$ for citalopram and 8700X, 8701Y, 8849R, 9432K and 9433L for escitalopram.
} 
dosage, LEXAPRO costs between 45 per cent and 262 per cent more than citalopram. ${ }^{62}$ There is no independent evidence as to their relative effectiveness. ${ }^{63}$

Figure 5 Prescribing switch: Cipramil to Lexapro (citalopram to escitalopram)

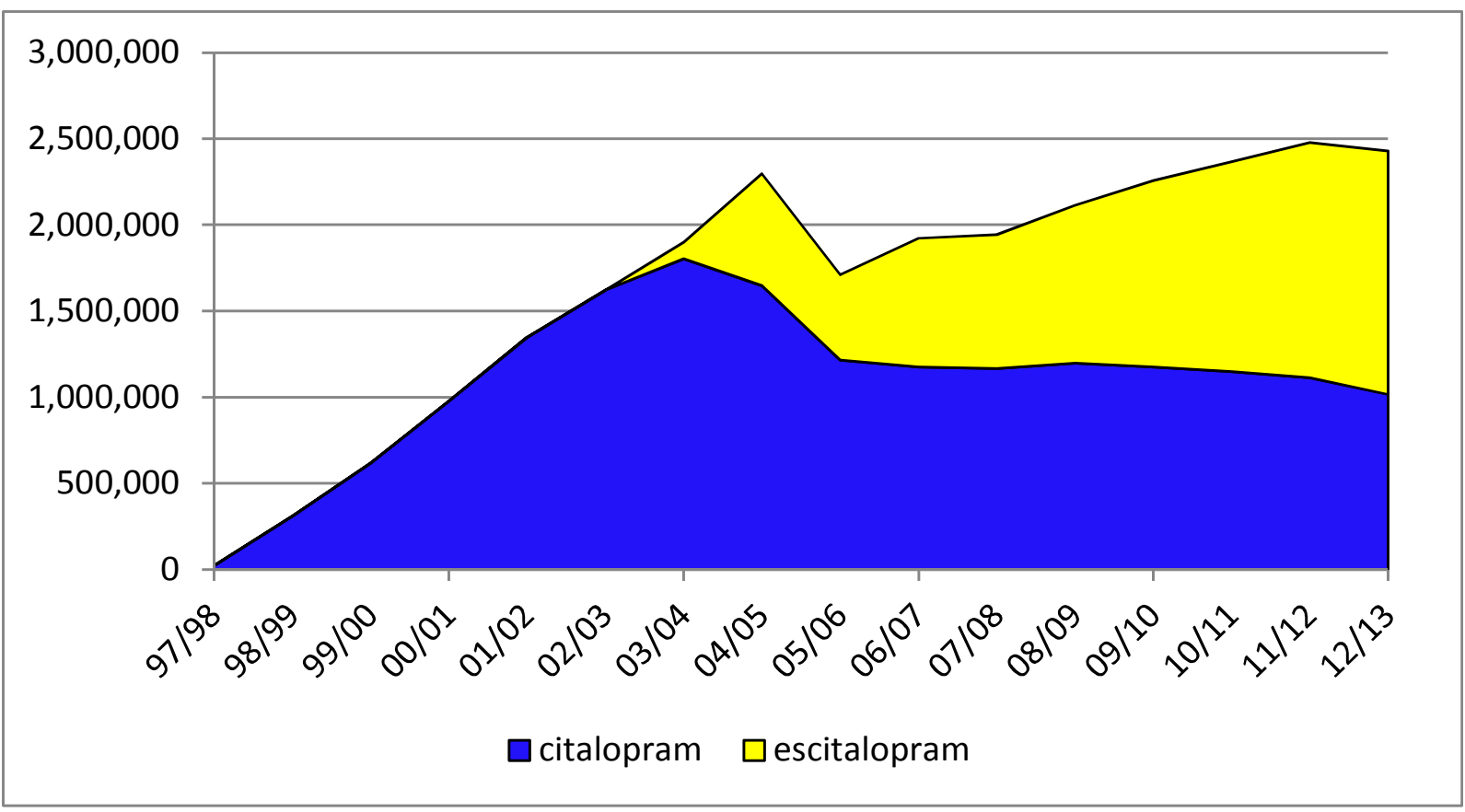

Source: Calculated from volume data from https://www.medicareaustralia.gov.au/statistics/pbs item.shtml

\section{Citalopram: overall findings}

Again this case emphasises the importance of having a high inventive step in order to achieve balanced outcomes from a patent system. The Federal Court's decision (Lindgren J) that the enantiomer was "inventive" because it was not obvious to try to find the enantiomer, flies in the face of the evidence that, at that time, it was well-known that one enantiomer might possess all of the pharmacological activity of the racemate. It also ignores the evidence that the owner of the racemic compound did precisely that - invested in identifying the enantiomer. The litigation commenced in 2005 when Alphapharm sued to revoke the patent. During the 4 years from July 2005 to July 2009 (when the enantiomer patent would have reached 20 years) PBS outlays on es/citalopram were \$A201 million. The requested term extension period does not expire until December 2012 - for the 4 years from June 2009 to June 2013 PBS expenditure on these drugs was $\$ 181$ million. According to a joint report by the Department of Health and Ageing and Medicines Australia, brand pharma's peak body, the cost of generic medicines to the PBS in 2010-11 was, on average, $30 \%$ of cost of patented medicines. ${ }^{64}$ The decision to uphold the enantiomer patent as valid was an expensive one, at an estimated taxpayer cost of $\$ A 47$ to 62 million. If the renewed effort to gain a 5 year term extension is upheld the cost of upholding the enantiomer patent will increase to between \$A123 and \$A164 million. ${ }^{65}$

\footnotetext{
${ }^{62}$ As at end October 2013. Calculated from data at http://www.pbs.gov.au/browse/body-system .

63 "Only one independent study has shown that escitalopram is more effective than citalopram, but in October 2011 it was reported that the company that sponsored the study had links to Lundbeck, the makers." (http://www.diffen.com/difference/Celexa vs Lexapro at 28 October 2013).

64 "Trends in and drivers of Pharmaceutical Benefits Scheme expenditure", (May 2013), p 34 Table 3. Available at www.pbs.gov.au/.../trends-in-and-drivers-of-pbs-expenditure.docx

${ }^{65}$ These estimates assume a price fall on generic entry of between 60 and 80 per cent.
} 
The term extension wrangle raises issues about the Patent Office's helpfulness towards patent holders. This helpfulness clearly does not extend to its duty to the consuming public or to the Australian taxpayer. It is this attitude - that allows a company to quickly obtain permission to undertake an action ten years after the deadline has expired - that underlies concerns about ceased patents. Technically such patents should not be able to be revived beyond the six month period following cessation. But there is substantial distrust around this issue and generic companies are wary of even ceased patents.

\section{Clopidogrel: enantiomers and combinations}

Clopidogrel is an anti-platelet agent that inhibits blood clotting. It is used to reduce the risk of stroke and heart attacks. The compound was originally patented in Australia with effect from 7 July 1983, ${ }^{66}$ but was not approved for marketing in a medicine until December 1998. Sanofi-Aventis filed 17 evergreening patents, of which four lapsed before grant and one is pending. The original patent expired in July 2003. The 12 evergreening patents are shown in Figure 6.

Figure 6 The clopidogrel patents

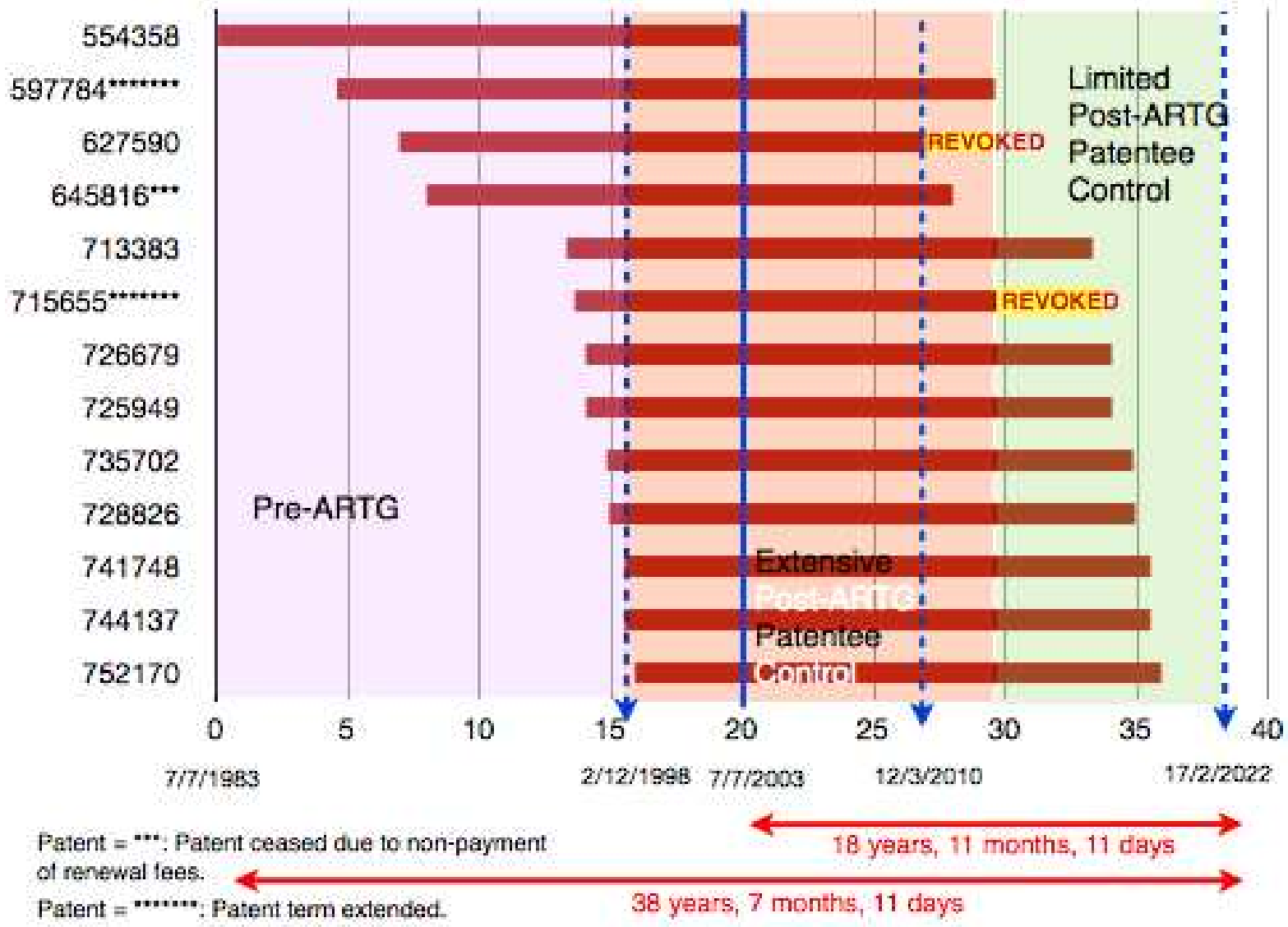

Source: Calculated from data extracted from AusPat and the ARTG.

There are three particularly interesting features in this case. The first is that a term extension was granted with respect to an evergreening patent (1988011292 (597784)) rather than the original compound (1983016637 (554358)). As this patent was found invalid and revoked it raises interesting questions about how the community is recompensed for the higher prices

\footnotetext{
${ }^{66}$ Application 1983016637 by Sanofi-Synthelabo granted on 6 February 1987. It claimed a priority date of 13 July 1982 from a French application.
} 
wrongly paid during the full term of the patent (including the patent term extension). The second is the grant of a patent (1997018884 (715655)) for a simple combination of two known drugs - clopidogrel and aspirin. Both clopidogrel and aspirin are out-of-patent yet a patent for a combination of the two was granted. The third is that the combination patent was also granted a 5 year term extension.

Before looking at these special features, we briefly consider the overall evergreening patent set. The first secondary patent (1988011292 (597784)) was filed in 1988 - for an enantiomer of clopidogrel. With the 5-year term extension the expiry date on this moved out to 4 February 2013. ${ }^{67}$ Two process patents were filed in 1990 and 1991 . The next spate of activity commenced with a formulation patent in 1996, followed by 11 further filings between 1997 and 2000. An application for a salt and polymorph of clopidogrel in 2005 was allowed to lapse. ${ }^{68}$ Another application - for the use of clopidogrel in combination with aspirin (acetylsalicylic acid or ASA) for treating patients with a history of atrial fibrillation - was filed in 2010 and remains pending. ${ }^{69}$ The twelve granted evergreening patents cover processes for manufacture (1990057546 and 1991079492); the enantiomer compound with the term extension; the clopidogrel/aspirin combination patent (also with a term extension) and eight patents with mixed claims. ${ }^{70}$ The last of these evergreening patents - the combination with aspirin - was due to expire on 17 February 2022, which would have given a theoretical overall patent term for clopidogrel of over 38 years, or over 23 years of market exclusivity.

\section{The enantiomer patent}

The original PLAVIX trade mark application for a medicine containing clopidogrel was lodged in December 1993 and was supplemented with a registered logo in June 1998. The medicine gained marketing (ARTG) approval in December 1998. As the original API patent expired in July 2003 this meant Sanofi had only 4 years and 8 months of market exclusivity in regard to the medicine. Sanofi was entitled to, and did, apply for a 5 year patent term extension. It did so however, not on the original API patent, but over the evergreening enantiomer patent. A term extension on the API patent would have provided $91 / 2$ years of market exclusivity. PLAVIX was the second biggest selling global pharmaceutical until its US patent lapsed in May $2012 .^{71}$ In 2011, the last year of full market exclusivity in the USA, PLAVIX ${ }^{72}$ earned US\$6.62 billion in the US market and a further US\$0.47 billion in other markets. ${ }^{73}$ Given the value of annual sales, a $9 \frac{1}{2}$ year period would have netted Sanofi considerable profit. However a term extension on the enantiomer patent pushed the market exclusivity period to over 14 years - an even greater profit.

It is interesting that the choice of which patent to extend seems to rest with the pharmaceutical company not with the government. After all it is Australian taxpayers who pay the higher price to Sanofi during the term extension period. One notes that the new expiry date - 4 February 2013 - was more than three years later than the patent expiry in

\footnotetext{
${ }^{67}$ Application 1988011292, filed 4 February 1988, granted 25 September 1990.

${ }^{68}$ Application 2005236046. An examiner's report was issued on 24 August 2010. The next renewal fee was not paid. It is possible that the examiner's report indicated little chance of grant.

${ }^{69}$ Application 2010201074. Examination had not yet been requested at 27 September 2013.

${ }^{70}$ For example composition and method of treatment (1997038526); formulation and product (1996074990); and composition, formulation and combination (1997037747 and 1997038526).

${ }^{71}$ http://www.reuters.com/article/2012/10/24/us-bristolmyers-results-idUSBRE89NONL20121024

72 Also selling as ISOCEVER ${ }^{\circledR}$.

${ }^{73}$ Calculated from data provided in http://www.genericsweb.com/index.php?object id=1086
} 
the United States. Sanofi was not required to produce any evidence that it had not yet obtained a risk-adjusted return on its R\&D investment.

Ultimately the validity of the enantiomer patent was challenged, but only in response to Sanofi suing to enforce it in September 2007 after becoming aware of imminent generic entry. Some $4 \frac{1}{2}$ years later the patent was invalidated, on the grounds that it involved no inventive step. As a result Sanofi's period of market exclusivity for the drug became based only on the original API patent, expiring in July 2003. Had Sanofi been content to extend the term of the API patent, it would actually have been some six months better off. Based on the low inventiveness standards in Australia Sanofi clearly judged that the strategy to seek the extension on the enantiomer patent was likely to be more profitable.

The cost to the Australian taxpayer of the higher prices paid for PLAVIX during the period of the injunction (September 2007 to March 2012) has been estimated at some $\$ A 60$ million. $^{74}$ Given that the revocation meant that the extended patent was never valid, generic companies would certainly have attempted market entry on the expiry of the original API patent ( 7 July 2003). This means that Australian taxpayers paid unsupported higher prices to Sanofi throughout the period from July 2003 to September 2007 as well as during the injunction period. The estimated additional cost to the taxpayer during this 5 -year period is between $\$ A 480$ and $\$ A 600$ million. ${ }^{75}$

While commercial parties can and do sue each other with respect to patent validity and infringement, there are no low-cost options for parties not engaged in the original challenge to recover excess prices paid after a patent has been declared invalid. Each would have to take its own legal action. Nor are there any precedents where third parties such as governments are concerned. Certainly there is no evidence that the Commonwealth government has taken any legal action to recover from Sanofi the estimated excess paid by the PBS due to higher prices during the period 7 July 2003 (when the original API patent expired) and 12 March 2010 (when the enantiomer patent was revoked). ${ }^{76}$ There has been a very substantial transfer of funds from Australian taxpayers to Sanofi-Aventis during a period now covered by no valid patent.

\section{The combination patent}

The second interesting feature about the evergreening clopidogrel patents is the grant of a patent for a simple combination of two known drugs - clopidogrel and aspirin. An application (1997018844) for this combination was filed on 17 February 1997 and granted on 25 May 2000. Aspirin has been made and used since $1899,{ }^{77}$ and clopidogrel was already known and patented. Clopidogrel is a blood thinning product and aspirin is used for the same purpose. Not only was a patent granted, but it was also given a full 5 year term extension as marketing approval was not gained until September 2009.

\footnotetext{
${ }_{75}^{74}$ Alphapharm submission to the Pharmaceutical Patents Review, p 20 (see footnote 40).

${ }^{75}$ Australian Senate Hansard, speech by Senator Bill Heffernan during debate on the Intellectual Property Laws Amendment (Raising the Bar) Bill 2011 (second reading), 27 February 2012 (http:// parlinfo.aph.gov.au/parlInfo/search/display/display.w3p;query=ld=\%22library\%2Flcatalog\%2F00585393\%22 )

${ }^{76}$ Though there are unconfirmed rumours that action has been taken to recover the higher prices paid during the two and a half year period when the injunction was in place. During this period 20.5 million scripts for clopidogrel were funded through the PBS (https://www.medicareaustralia.gov.au/statistics/pbs item.shtml items $4179 \mathrm{Y}$ and $8358 \mathrm{X})$.

${ }^{77}$ http://en.wikipedia.org/wiki/History_of_aspirin
} 
The combination product had four trademarked names in Australia, all owned by Sanofi. COPLAVIX ${ }^{\circledR}$ was registered from January 2003 and a matching logo registered from September 2010. DUOCOVER ${ }^{\circledR}$, DUAPLAVIX ${ }^{\circledR}$ and DUALPLAVIX ${ }^{\circledR}$ were all registered in 2005 . The granted period of market exclusivity for the combination drug (from ARTG approval to extended patent expiry) was over 12 years.

Was this patent justified? Australia abandoned the synergy standard for the grant of patents on combinations of known things in $1980 .^{78}$ Does the combination of these two compounds generate sufficient new knowledge or sufficient additional therapeutic benefit to justify patent grant? Presumably the new knowledge was that it is safe to take both products though we do not know whether there was independent information on this. ${ }^{79}$ Certainly the combination is seen as a useful treatment in acute situations, but again it is unclear to what extent this was known before 1997. Perhaps the strongest evidence on whether a patent should have been granted is the fact that when it was challenged, the patent owner did not defend it. Apotex challenged the patent in April 2012 and it was revoked on 29 May 2012, clearing the way for more substantial generic competition. Sanofi did not defend the patent and the First Directions hearing decision simply states that the patent is revoked. ${ }^{80}$

Australia provides 5 years of data exclusivity, meaning that the clinical trial data need for ARTG market approval cannot be used to support generic entry until 5 years have elapsed. Where the "improved" drug involves any such trials - as is the case when two known compounds are combined - this new privilege provides a significant period during which higher prices can be charged. Double-dipping into both data exclusivity and the patent system is neither needed nor justified. Indeed use of the patent system to support such minor improvements undermines the innovation goals of the patent system.

As at October 2013 there is a single generic brand of the COPLAVIX combination product on the market - though it looks like three brands as it is badged with different pharmacy chain labels. ${ }^{81}$ Sanofi markets this product both as COPLAVIX and Duocover. ${ }^{82}$ PLAVIX itself is marketed with two treatment indications, one of which is its combination with aspirin to treat acute coronary syndrome.

Effectively Sanofi had 2.7 years of market exclusivity on this combination product. ${ }^{83}$ Had neither the combination product nor the enantiomer patent been granted, market competition could have commenced in 2003.

\footnotetext{
${ }_{78}^{78}$ Minnesota Mining \& Manufacturing Co v Beirersdorf (Australia) Ltd (1980) 144 CLR 253.

${ }^{79}$ Clinical trials were needed to demonstrate that the combination of these two blood thinning treatments was safe and worked better than a placebo. This raises many issues about the funding of clinical trials for treatments which are not new or where the key issue is effectiveness compared to other existing treatments. The earliest information we have been able to find on this combination treatment is from 2000 and 2001 which post-dates the patent application. http://archinte.jamanetwork.com/article.aspx?articleid=217555 and http://www.ccjm.org/content/69/5/377.full.pdf.

${ }^{80}$ https://www.comcourts.gov.au/file/Federal/P/NSD612/2012/actions

81 http://www.pbs.gov.au/medicine/item/9296G (7 October 2013).

82 The marks DUAPLAVIX and DUALPLAVIX are not currently listed on the PBS and so presumably are not being sold in Australia.

${ }^{83}$ In fact one generic product is on the market - the fact of only one competitor (Apotex) suggests that Sanofi has licensed the product. However the existence of a generic does mean that prices paid are slower than they would have been without the presence of a generic, but higher than if there had been competition between generic companies.
} 


\section{Clopidogrel: overall findings}

This case adds to the evidence from the des/venlafaxine case that the rules for granting patents for combinations of known things need urgent attention. They allow for the grant of patent for things that offer no new knowledge, let alone the "significant advance in what is known or used" that is meant to be the standard in Australia. ${ }^{84}$ The clopidogrel case also confirms that improved procedures are needed to recoup losses when patent are declared invalid. The completely unjustified transfer of some $\$ A 480$ and $\$ A 600$ million from Australian taxpayers to Sanofi is a very poor outcome and was only possible because of the low inventiveness standard in the Australian patent system.

The 2009 Full Federal Court decision that this enantiomer lacked any inventiveness stands in contrast to its decision just 3 months earlier in regard to citalopram's enantiomer. ${ }^{85}$ This second decision has a far sounder economic basis and does much to protect the public interest (and purse). The Patent Office has now moved to suggest that patents will rarely be granted for enantiomers. Our cases have two further examples of enantiomers, one of which remains on the books. It would be useful if the patent Office re-examined all enantiomer patents, including the esomeprazole ones discussed in the next case.

\section{Omeprazole / esomeprazole: enantiomer and an enteric coating!}

Globally, the most famous example of enantiomer evergreening is AstraZeneca's omeprazole (PRILOSEC as it is known in the USA or LOSEC elsewhere) and esomeprazole (NEXIUM). Known as a proton-pump inhibitor, in the human body LOSEC and NEXIUM form the same active drug which stops gastric acid production. LOSEC is the racemic version (with both enantiomers), while NEXIUM is the S-enantiomer alone. They are used for the treatment of dyspepsia, peptic ulcers and reflux.

The Australian patent underlying LOSEC (1979046027 (529564)) has been surrounded by a further 61 patents which extend the expiry date from 11 April 1999 to 7 May 2027 - an additional 28 years beyond the originally approved term (see Figure 7). Two of these patents have expired, and 35 are ceased. Ceased patents can be re-instated by the late payment of renewal fees. ${ }^{86}$ This leaves 24 evergreening patents still in force.

The patent underlying LOSEC commenced on 11 April 1979 and expired on 11 April 1999. Market approval at the end of 1988 gave Astra an anticipated 101/3 years of market exclusivity over the drug LOSEC (although it had market exclusivity of the compound used to develop LOSEC from April 1979). ${ }^{87}$ The first evergreening patent (1984025257 (563842)) was for a variant on the compound - omeprazole salts. A further three applications, made in the period to 1988, including a formulation "invention" for an enteric coating (1987071912 (601974)), which was subsequently litigated. From 1990 to 2007 a large number of es/omeprazole patents were filed in Astra's name (Hässle is a subsidiary of Astra, later AstraZeneca). As Figure 8 shows, almost all applications were granted - only four were allowed to

\footnotetext{
${ }^{84}$ Explanatory Memorandum, Intellectual Property Laws Amendment (Raising the Bar) Bill 2011, p. 42.

${ }^{85}$ Apotex v Sanofi-Aventis [2009] FCAFC 134.

${ }^{86}$ Normally this should be done within 6 months of cessation and there is a right to appeal against a decision to revive a ceased patent. The citalopram case, where the patent office granted a request for a 10 year extension to the normal time frame for an application for a patent term extension, increases the uncertainty about the status of ceased patents.

${ }^{87}$ For some reason actual market entry was delayed by nearly 18 months.
} 
lapse. The peak patenting period was from 1997 to 2000 - i.e. the few years before LOSEC's replacement NexIUM came on the market.

\section{Figure $7 \quad$ Omeprazole / esomeprazole: patents granted in Australia}

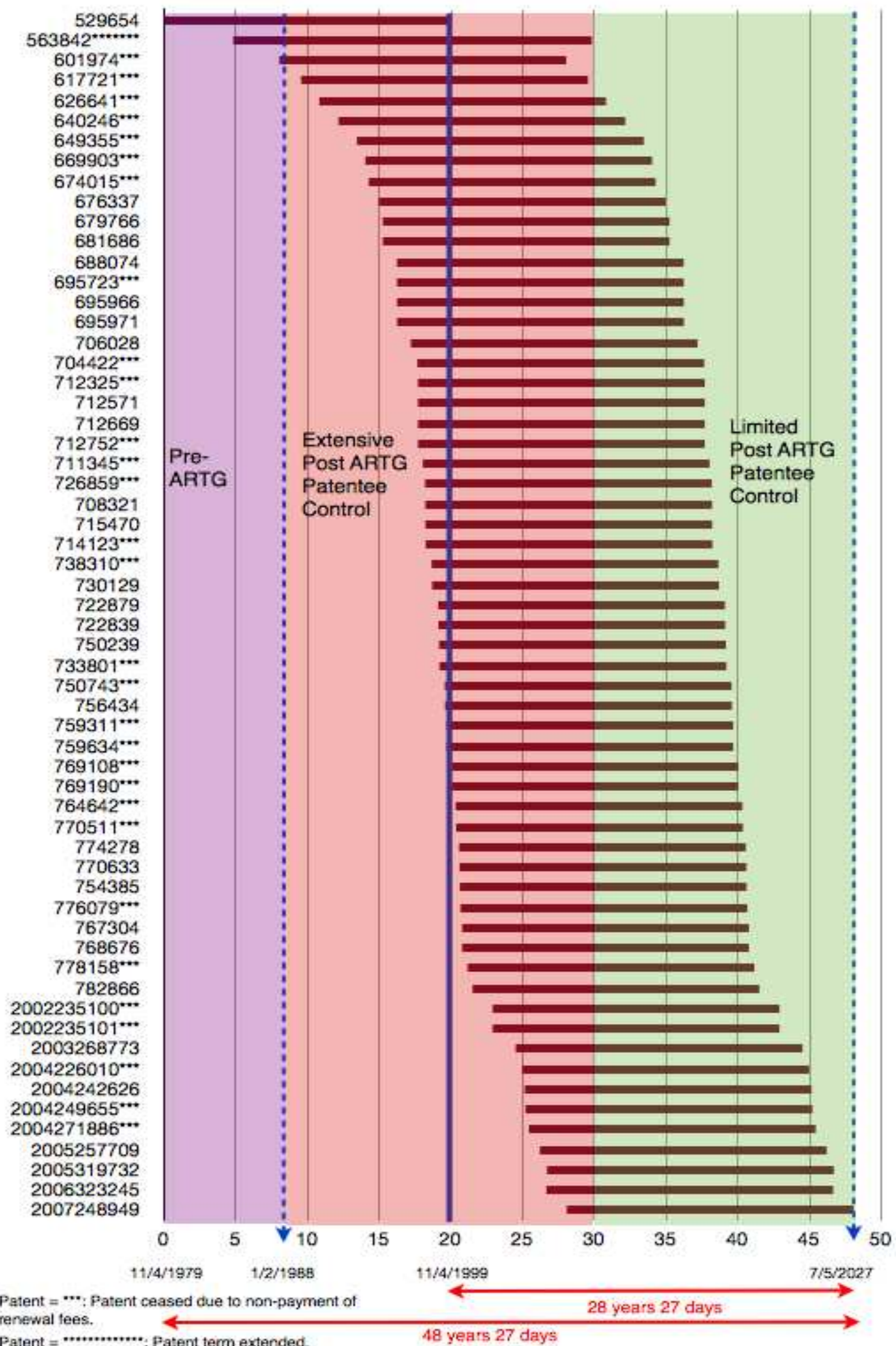

Source: Calculated from data from AusPat and the ARTG. 
Astra has two trademarked omeprazole products, of which the most famous is LOSEC. LOSEC was approved for marketing on 1 December $1988 .^{88}$ There was brief generic competition from May 1999 to August 2003. Alphapharm attempted to enter the market when the original patent expired, but was sued for infringement by Astra on the basis of the 1987071912 formulation patent. ${ }^{89}$ At that time 17 evergreening patents had been granted. The Full Federal Court upheld the decision revoking the patent on the ground that there was no inventive step in the enteric coating of a tablet form of omeprazole. ${ }^{90}$ The High Court overturned this decision ${ }^{91}$ in a judgement which Lawson has referred indicating the quantum of inventiveness required for a patent was "almost a per se rule so that the quality of obviousness will almost never be relevant in assessing patentability" (Lawson 2008: 44). This affirmation of an extraordinarily low inventiveness requirement for grant of a patent was an expensive one for Australian taxpayers.

Figure 8 es/omeprazole patent applications and grants by Hässle/Astra

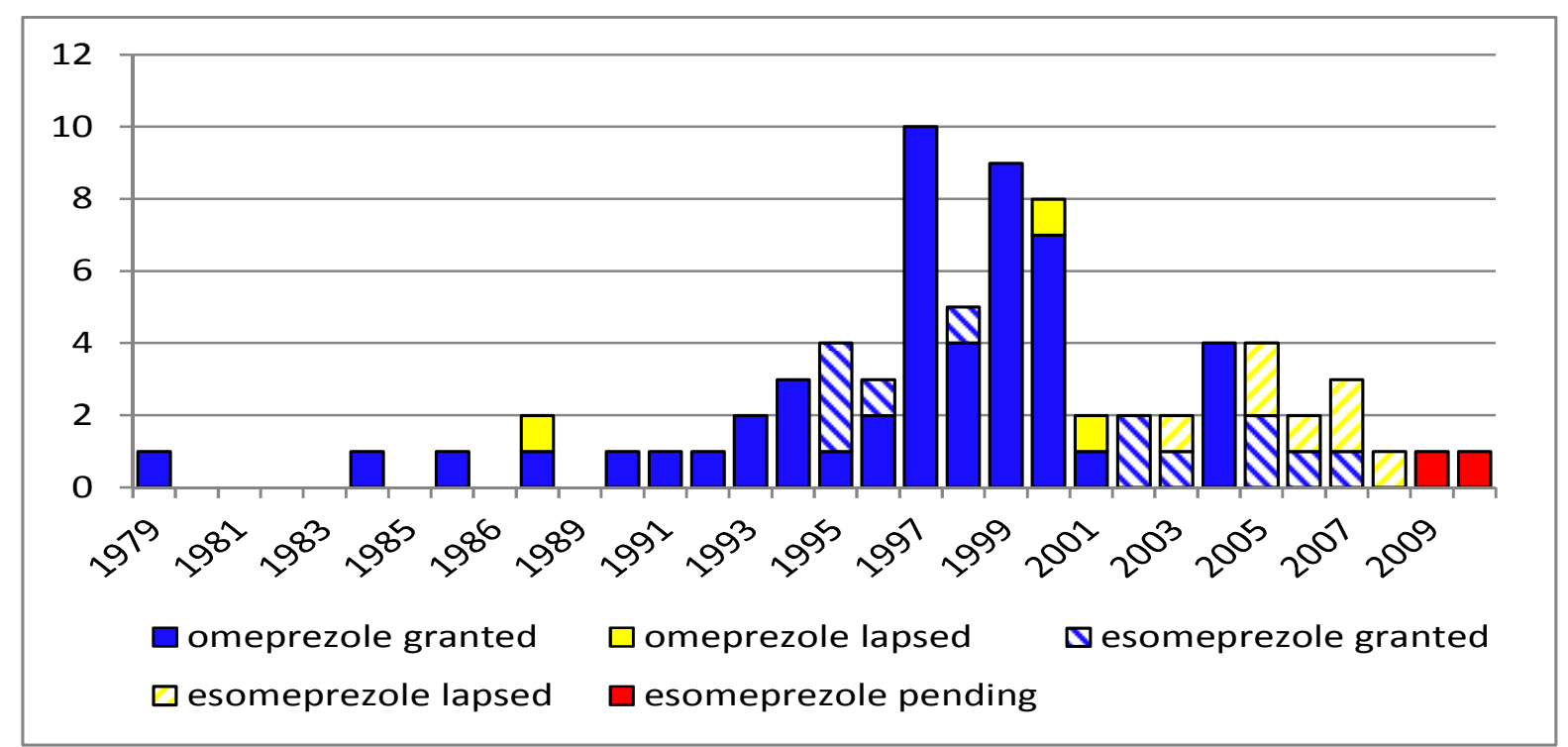

Source: Calculated from data from AusPat. Esomeprazole patents were defined on basis of esomeprazole in abstract or claims or enantiomer in abstract.

Between May 1999 (just after the original patent expiry) and April 2006 (just after the formulation patent expiry), PBS outlays on LOSEC were \$A1.413 billion. Considering only enteric coated versions, outlays were $\$ A 1.214$ billion. With current pricing policies, the invalidation of the formulation patent would have saved taxpayers a minimum of \$A194 million and a further $\$ A 412$ million presuming prices fell by a modest 50 per cent. $^{92}$

The evergreening formulation patent was very successful in restraining generic competition. Marketing approval for another generic version of omeprazole was not provided until 14 June 2007, shortly after the litigated patent expired. There are currently four dosage versions of omeprazole listed on the PBS, with generic competition for the two $20 \mathrm{mg}$ tablet

\footnotetext{
${ }^{88}$ The other is ANTIMAX, approved for the market on 18 August 1999. This is not listed on the PBS.

${ }^{89}$ Aktiebolaget Hässle v Alphapharm Pty Ltd [1999] FCA 628 (12 May 1999) at 4.

${ }^{90}$ Aktiebolaget Hassle v Alphapharm Pty Limited [2000] FCA 1303 (9 October 2000).

${ }^{91}$ Aktiebolaget Hässle v Alphapharm Pty Ltd (2002) 212 CLR 411 (Astra).

${ }^{92}$ Calculated from PBS data available at https://www.medicareaustralia.gov.au/statistics/pbs item.shtml using item numbers 1326T, 1327W, 8331L, 8332M, 8333N, 9109K and 9110L (all pure omeprazole products) and assuming an initial 16 per cent rice fall followed by a fall to 50 per cent of the initial price.
} 
forms. ${ }^{93}$ A second generic omeprazole product was not approved until 8 March 2012 - in this case a $10 \mathrm{mg}$ enteric-coated tablet in a blister pack. ${ }^{94}$ Why the lack of substantial generic competition after 2007 ?

In 2001 Astra had introduced the enantiomer version of LOSEC into the market esomeprazole, marketed as NexIUM. It appears to be supported by 12 of the 62 patents granted for omeprazole or esomeprazole. ${ }^{95}$ The earliest of these clearly identifiable omeprazole patents was filed on 7 June 1995 (Figure 8). The last of the currently in force esomeprazole patents ceases on 4 December $2026 .{ }^{96}$ Heavy marketing resulted in a "prescribing switch" to NexIUM, substantially reducing the size of the omeprazole market. As Figure 9 shows, the market for NEXIUM now far exceeds the market for LOSEC. Generic versions of omeprazole have recently reached 47 per cent of the omeprazole market, but a mere 12 per cent of the combined es/omeprazole market.

There are six different trademarks for esomeprazole, the best known being Nexium which was approved for the market on 28 March 2001. ${ }^{97}$ Goldacre (2012: 250) provides data for marketing expenditure during this switch overseas. ${ }^{98}$ Prior to the switch LOSEC was the most heavily promoted drug in the market, with expenditure of UA\$100 million in 2000. In 2001 \$US500 million was spent promoting NEXIUM.

\section{Figure 9 Prescribing switch: LOSEC (omeprazole) to NEXIUM (esomeprazole)}

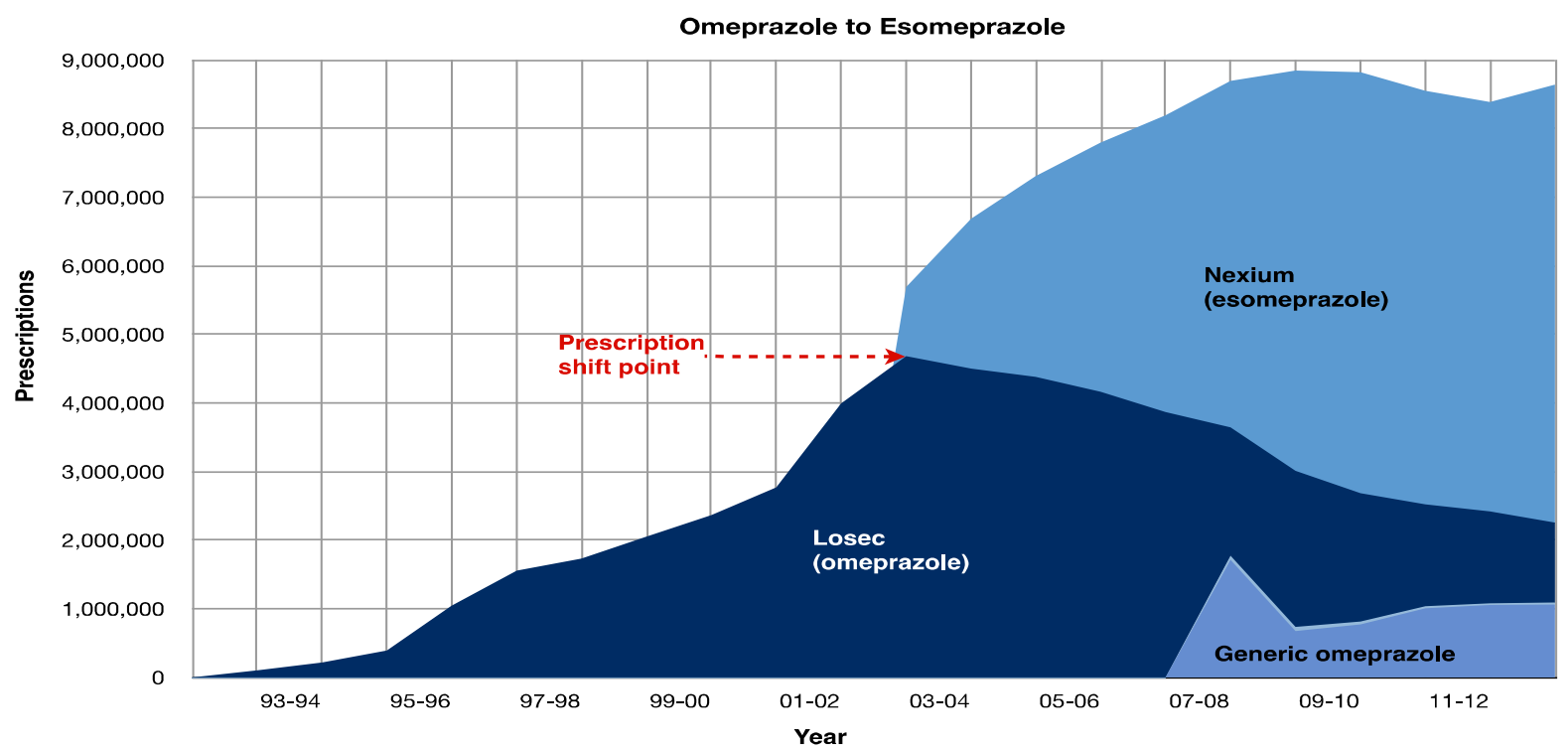

Source: Calculated from data available from https://www.medicareaustralia.gov.au/statistics/pbs item.shtml

\footnotetext{
${ }^{93}$ http://www.pbs.gov.au/pbs/search?term=omeprazole+\&search-type=medicines (5 October 2013). There is generic competition for both regular and enteric coated $20 \mathrm{mg}$ tablets.

${ }^{94}$ OMEPRAZOLE SANDOZ (Sandoz) ARTG Entry 176178; approval Date: 8 March 2012.

${ }^{95}$ A search for the word esomeprazole in the abstract or claims of patents or enantiomer in the claims identifies 21 applications filed by AstraZeneca, of which 12 were granted and two are pending.

${ }^{96}$ Though ceased application 2007248949 would run to 7 May 2027 if it were revived.

${ }^{97}$ Other esomeprazole products are NEXIUM HP7 (ARTG approved on 3 December 2003), NEXIUM IV (ARTG approved on 27 July 2004), OMPRAL (ARTG approved on 1 November 2005), MoPRA (ARTG approved on 1 November 2005) and VIMOVO (ARTG approved on 25 October 2011). Of these only NEXIUM HP7 and VIMOVO are on the trade mark register, both owned by Astra.

${ }^{98}$ As this is before the introduction of voluntary reporting of "education" expenditure by members of Medicines Australia [sic] parallel data are not available for the Australian market.
} 
As yet there are no generic esomeprazole products listed on the PBS. The lack of competition with NEXIUM suggests that the evergreening patents on esomeprazole are still preventing market entry. Astra still promotes NEXIUM heavily - it reportedly spent US\$478 million promoting NEXIUM in 2011. ${ }^{99}$ In financial 2012 total outlays on the two drugs were $\$$ A286million. ${ }^{100}$ The only omeprazole brand listed on the PBS is NEXIUM and this now has an 82 per cent market share. Had this market component been subject to generic competition as would have been the case had the enantiomer patent been invalidated - taxpayers would have been saved between \$A24 and \$A32 million a year.

\section{E. Statins: LIPITOR and predatory generic behaviour}

The "powerful exclusive right" of a patent enables the owner to control the price and availability of a patented product. Where prices are inelastic there is a strong incentive for competitors to develop substitutable products that they too can patent. In pharmaceuticals this leads to the development of "me-too" drugs targeting lucrative markets with products providing a similar therapeutic effect yet sufficiently different to meet the low patent system requirements for novelty and inventiveness.

Statins (HMG-CoA reductase inhibitors) are a set of drugs used to lower cholesterol levels. Reduced cholesterol levels are thought to be beneficial because they reduce the incidence of cardiovascular disease. ${ }^{101}$ There has been considerable investment in statin research and there are now many statin drugs on the market. These seem to have been associated with some improvement in therapeutic effect, particularly the more effective management of side-effects. The issue still arises as to the net social benefit of so many closely similar products and whether use of the patent system to achieve this outcome is welfareenhancing.

LIPITOR (atorvastatin) is a case with two particularly interesting features. Firstly, market entry by generics was far from orderly. A single evergreening patent extended the period of effective market exclusivity by a mere five months, yet was challenged and revoked. A global out-of-court settlement between Pfizer and the successful challenger generic company, Ranbaxy, allowed Ranbaxy exclusive rights to enter the Australian market three months before the original patent expired. Ranbaxy's marketing strategy disrupted the normal process of generic entry.

The second interesting feature about LIPITOR is that Pfizer was granted a patent for an invention combining atorvastatin with amlodipine, both known compounds. As with venlafaxine and clopidogrel this again indicates the high cost to the Australian economy of the very low inventiveness standard for patenting combinations of known things.

\footnotetext{
${ }^{99}$ See Gardiner Harris, Prilosec's Maker Switches Users To Nexium, Thwarting Generics, Wall Street Journal, 6 June 2002, available at http://online.wsj.com/article/0,SB1023326369679910840,00.html (28 September 2013). The original AstraZeneca patent for the compound marketed as PRILOSEC is US 4,786,505 (application 07/040,491) filed 20 April 1987 and granted 22 November 1988. The original patent for the compound marketed as NEXIUM (US 6,143,771; application number 09/419,456) filed 15 October 1999 and granted 7 November 2000.

${ }^{100}$ Calculated from data available at http://www.pbs.gov.au/statistics/2011-2012-files/table-9b.pdf (5 October 2013).

${ }^{101}$ Though there is some dispute as to whether lowering cholesterol actually does reduce cardiac disease - see for example Daniel Steinberg, The Cholesterol Wars: The Skeptics vs. The Preponderance of Evidence. Academic Press, 2007, pp. 6-9 and Reginald Marsh, "Cholesterol levels have negligible correlations with cardiovascular incidents", The New Zealand Medical Journal, 125: 1364, 2012.
} 
LIPITOR is reported as the best-selling pharmaceutical in history: for all but one of the years between 2003 and 2011, it was the top selling drug in the US market, with sales over this nine year period reported at US\$54.5 billion. ${ }^{102}$ In the first year of generic competition (2012) US sales were about US\$1.6 billion $^{103}$ - a considerable drop from the 2011 sales of US\$7.4 billion the previous year.

LIPITOR was approved for Australian market entry on 17 December 1996. The original patent, filed in 1987, expired on 18 May 2012 after a 5-year extension. There was no requirement for Pfizer to show that the term extension was needed to fund the relevant R\&D. During the 5 year term extension the PBS spent \$A3.1 billion on LIPITOR. ${ }^{104} \mathrm{~A}$ substantial fraction of that outlay was above marginal cost pricing to reimburse Pfizer for their R\&D outlays - indeed it seems likely that the profit from sales in Australia more than equalled actual outlays on R\&D for this product.

LIPITOR is surrounded by just 14 evergreen patents, though it also filed another 19 applications which were withdrawn or allowed to lapse before grant (Figure 10). The original API patent had claimed racemic atorvastatin calcium. The first evergreening patent was filed three years after the original API patent, asserting the isolated R-enantiomer was 10 times more active than the racemic compound. This enantiomer patent was also granted a term extension of just over two years bringing its expiry date to 25 September 2012, five months after expiry of the original patent. Ranbaxy successfully challenged this patent. It was revoked on the grounds of false suggestion - the claims as to the relative efficacy of the enantiomer. ${ }^{105} \mathrm{~A}$ further eight evergreening patents do not seem to have prevented generic entry. The five patents on the combination of atorvastatin and amlodipine have been more successful in preventing generic entry.

\section{Generic entry}

A challenge to a patent covering just five months in the market indicates just how lucrative pharmaceutical markets are, both for originator companies and for first generic entrants.

As part of its out-of-court settlement with Pfizer, Ranbaxy gained the unusual advantage of entering the atorvastatin market three months before patent expiry. Ranbaxy thus gained a supply and price advantage not normally available to generic companies. Instead of charging a higher than normal price for a generic during this period, Ranbaxy cut the ground from its rivals by providing pharmacies with 3 months' free supply of its version of atorvastatin $\left(\right.$ TROVAS $\left.^{\circledR}\right)$ together with an unprecedented $90 \%$ discount for further orders. ${ }^{106}$ This

102 Calculated from annual data on top 100 or top 200 selling drugs by US sales value available from http://www.drugs.com/top200.html (3 October 2013).

${ }^{103} 2012$ sales data are not provided for 2012 on http://www.drugs.com/top200.html, but can be inferred from ranking between enoxaparin with sales of US\$1.7 billion and LUCENTIS with sales of US\$ 1.6 billion

104 Calculated for the 5 year period July 2007 to June 2012, using data for item codes 8213G, 8214H, 8215J, 8521L, 9230T, 9231W, 9232X, 9233Y and https://www.medicareaustralia.gov.au/statistics/pbs item.shtml. A small proportion of this outlay goes to pharmacists for dispensing the drug.

${ }^{105}$ The patent was held to be invalid as it had been obtained by false suggestion (Ranbaxy Australia $v$ WarnerLambert [2008] FCAFC 82). Warner-Lambert is a Pfizer company. Pfizer also settled out of court with Ranbaxy over a US patent dispute related to LIPITOR.

${ }^{106}$ Harvey, K (2012), 'Companies tussle over market share for anti-cholesterol drug Lipitor and its generic equal', The Conversation (18 May 2012): http://theconversation.com/companies-tussle-over-market-share-foranti-cholesterol-drug-lipitor-and-its-generic-equal-7088 and Sue Dunleavy, 'Generic drug supply exposes flaw in subsidy scheme', National Affairs, 28 May 2013 at http://www.theaustralian.com.au/nationalaffairs/policy/generic-drug-supply-exposes-flaw-in-subsidy-scheme/story-fn59nokw-1226368696733\#. 
completely decimated the marketing strategies of competing generic companies. ${ }^{107}$ Competing firms, which had geared up to enter this market, were faced with zero demand for the initial months.

\section{Figure 10 Atorvastatin: LIPITOR and CADUET patents}

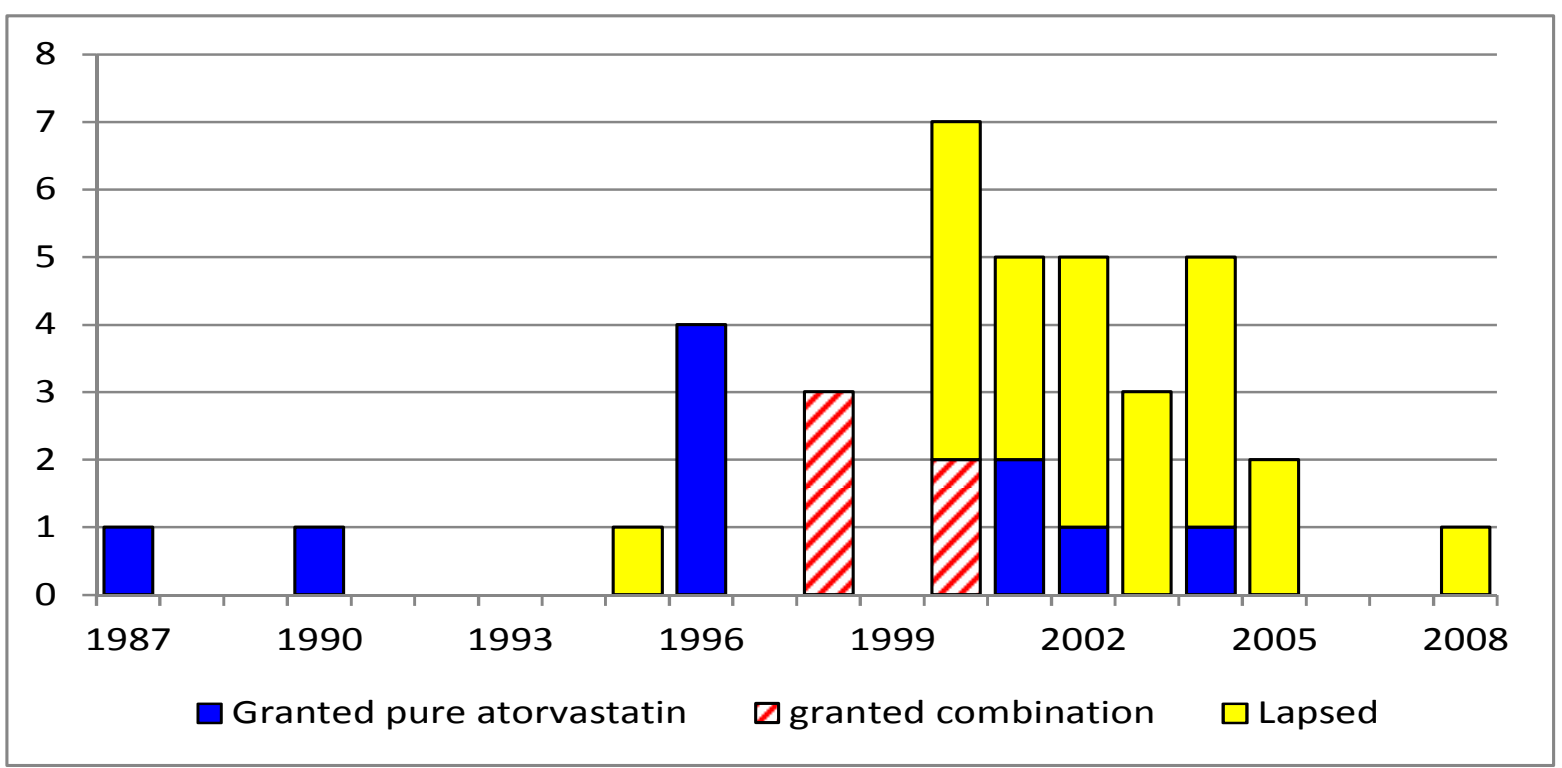

Source: Calculated from data from AusPat.

This behaviour would seem on its face to be anti-competitive ${ }^{108}$ and has certainly deprived rivals of an anticipated share of the atorvastatin market. The situation is further complicated by Pfizer's launch of its own "generic" brand and its full-page "information" direct to the public about the continued availability of LIPITOR. The fines for this breach of regulations prohibiting direct-to-consumer advertising were paltry compared to the profit from the drug each month. ${ }^{109}$ Such games go well beyond ordinary rivalrous competition, raising concerns about sustainability in the generics industry if no action is taken to enforce standards.

Yet Australian taxpayers still pay a much higher price for generic atorvastatin - the action by Ranbaxy provides a very large windfall gain to pharmacists and no benefit to the taxpayers who fund the PBS. While the PBS price review mechanism will over the longer term achieve good savings, the delays built into the system are overly generous to pharmacists and a poor bargain for taxpayers.

\section{Combination with amlodipine}

Several of the evergreening patents are for the combination of atorvastatin and amlodipine (Figure 10). This combination treats high cholesterol and high blood pressure simultaneously. Neither atorvastatin nor amlodipine are still in patent. But the grant of a new patent for the combination provides a new period without market competition - until 20 July 2020, as a term extension of nearly two years was granted (Figure 11). Again this

\footnotetext{
107 Sathebennur, M. (2012) "Alphapharm out-dated: Ranbaxy", Pharma in Focus (30 April 2012).

108 Particularly since the out-of-court settlement may have included a financial inducement from Pfizer to Ranbaxy for undercutting the generic market.

109 Pharmacy Daily reported that Pfizer was fined $\$ 20,000$ by Medicines Australia for such advertisements (http://www.pharmacydaily.com.au/news/pfizer-fined-over-lipitor-ads/2874) while the Australian Doctor reports $\$ 50,000$ fines (http://www.australiandoctor.com.au/news/latest-news/pfizer-fined-\$50k-for-lipitorads). Small change compared to the income from the PBS.
} 
raises the question of the standard required for grant of a patent when known things are combined. If the synergy doctrine had remained in place would this patent have been granted? The main advantage of combining these two drugs in a single tablet would seem to be increased patient compliance. How does this benefit compare to the cost?

This product is marketed under three brand names CATATIN, CADUET and CADUPINE. CADUET was approved by the ARTG on 21 March 2007. These products are in the F2 formulary, but as all are owned by Pfizer there is no price competition so the normal process which reduce F2 drug prices are absent. For the eight dosages listed on the PBS in October 2013, prices ranged from $\$ A 42.21$ for $5 \mathrm{mg}$ of amlodipine combined with $10 \mathrm{mg}$ of atorvastatin to $\$ A 102.30$ for $10 \mathrm{mg}$ of amlodipine combined with $80 \mathrm{mg}$ of atorvastatin. The market for the combination drug is small compared to pure atorvastatin- PBS outlays were $\$ A 362$ million compared to $\$ A 6,618$ million in FY 2012-13. But the CADUET share of the market for the two drugs has grown from less than one per cent in 2006-07 to 12.5 per cent in 2012-13. ${ }^{110}$

\section{Figure 11 Atorvastatin: LIPITOR and its evergreening patents}

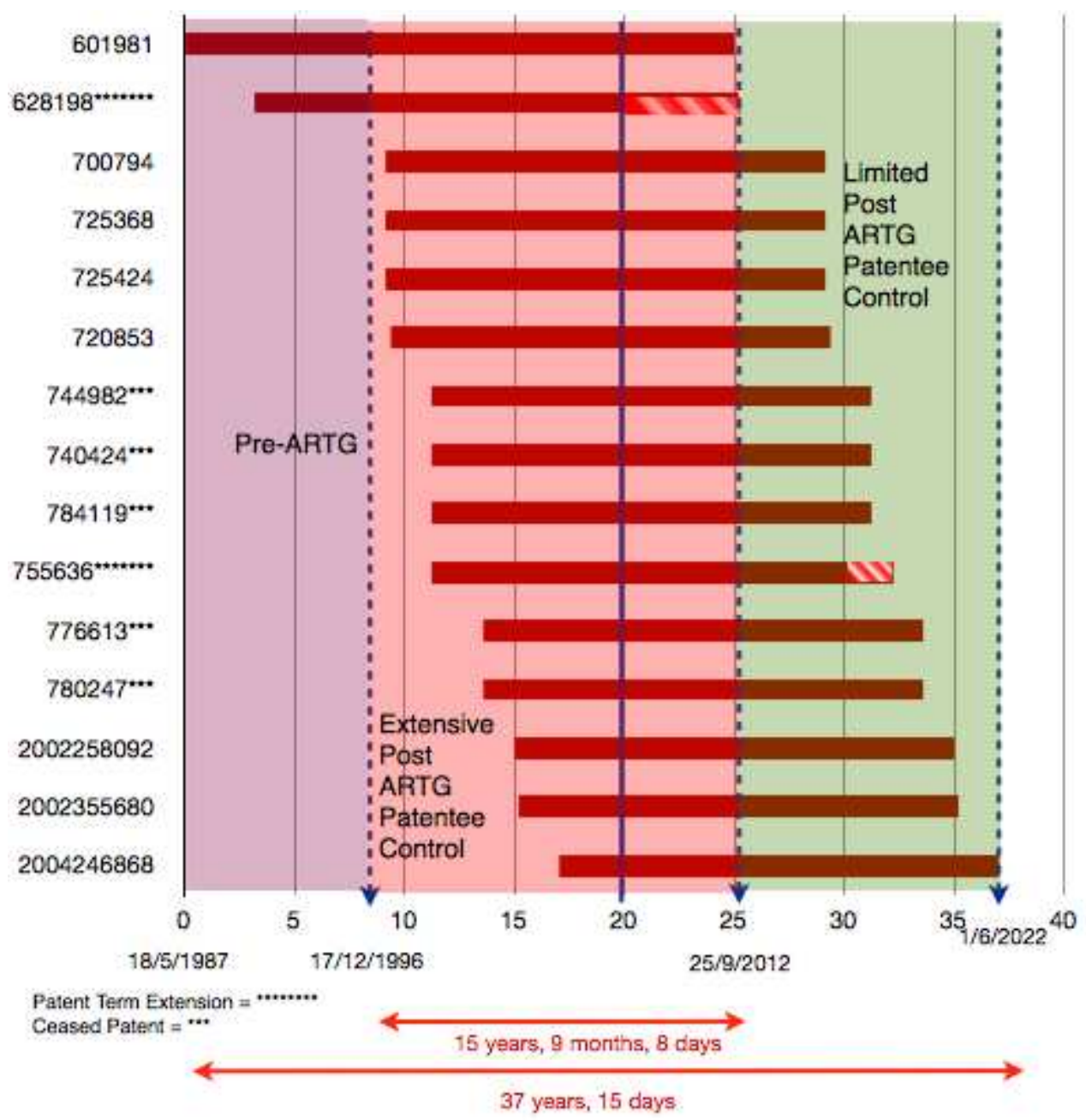

Source: Calculated from data from AusPat and the ARTG.

This case again points to the high cost of low patentability standards. Even though the enantiomer patent only provided an extra five months market exclusivity, this was sufficiently profitably to prompt a challenge. The out-of-court settlement consequent on

\footnotetext{
${ }^{110}$ Calculated from data available from https://www.medicareaustralia.gov.au/statistics/pbs item.shtml using item codes 9049G, 9050H, 9051J, 9052K, 9053L, 9054M, 9055N and 9056P for CADUET.
} 
that challenge severely disrupted generic entry to the substantial benefit of one firm and many pharmacy owners. Brand companies leverage these advantages with marketing expenditure targeted to achieve changes in prescribing behaviour which are not supported by any scientific evidence as to increased effectiveness.

\section{F. Alendronic acid: how many can you get?}

FOSAMAX (alendronic acid or alendronate) is a bisphosphonate drug used for osteoporosis and other bone diseases. It was approved for marketing in Australia on 7 July 1995. The combination of alendronic acid and colecalciferol (vitamin $\mathrm{D}_{3}$ ) was approved for sale on 14 May 2008 and is marketed as FOSAMAX PLUS. The further combination of alendronate, vitamin $\mathrm{D}_{3}$ and calcium carbonate was approved by the ARTG on 25 March 2010 and is marketed as FOSAMAX PLUS D-CAL.

The original API compound patent was never filed in Australia. The first Australian patent filed was an evergreening patent, filed in June 1990 and expired in June 2010. Had the original compound patent been filed, the expiry date would have been in 2008 , assuming a term extension. This first (evergreening) patent was for a variation to the original compound, a trihydrate salt of alendronate. On the basis of this first patent alone the claimed period of effective market exclusivity for FOSAMAX is nearly 15 years. In the US market generic alendronic acid was approved for sale in early 2008. In the preceding five years, US sales totalled US\$7.1billion. ${ }^{111}$

Hemphill and Sampat provide a useful analysis of the effective period of market exclusivity for FoSAMAX in the USA. The entry of the first generic product to the US market occurred 4 years before the underlying patents had been due to expire, producing a sharp drop in revenue. FoSAMAX had already had 12.5 years of market exclusivity when the first generic entered the market. Further it had a set of evergreening patents that took final patent expiry out to 2019. The successful challenge of the evergreening patent due to expire in 2013 can indeed be seen as bringing generic competition in 4 years early. Equally it can be seen as preventing an unjustified further 11 years of market exclusivity and very high prices (Hemphill and Sampat 2012: 337).

Merck obtained a further 50 evergreening patents in Australia. These covered just about anything and everything to do with alendronate - modified compounds, methods of treatment, formulations and compositions, processes, intermediate process ingredients, methods of use, dosages, and combinational compositions combined with methods of treatment. In addition to the 51 granted patents a further 11 applications were allowed to lapse. As the data in Figures 12 and 13 show, the period over which Merck filed these evergreening applications was quite extensive. If all are upheld, and are effective in preventing generic entry, the claimed period of market exclusivity for FoSAMAX is over 31 years and for FOSAMAX PLUS D-CAL is nearly 21 years. The last evergreening patent is not due to expire until 4 December 2026.

\footnotetext{
${ }^{111}$ Calculated from data on top 200 US drug sales available at http://www.drugs.com/top200.html (3 October 2013). During this 2003-07 period FosamaX ranked between $17^{\text {th }}$ and $24^{\text {th }}$ on the top 200 drugs list, but fell out of this completely when generics entered.
} 
Figure 12 Merck's alendronic acid patents and patent applications

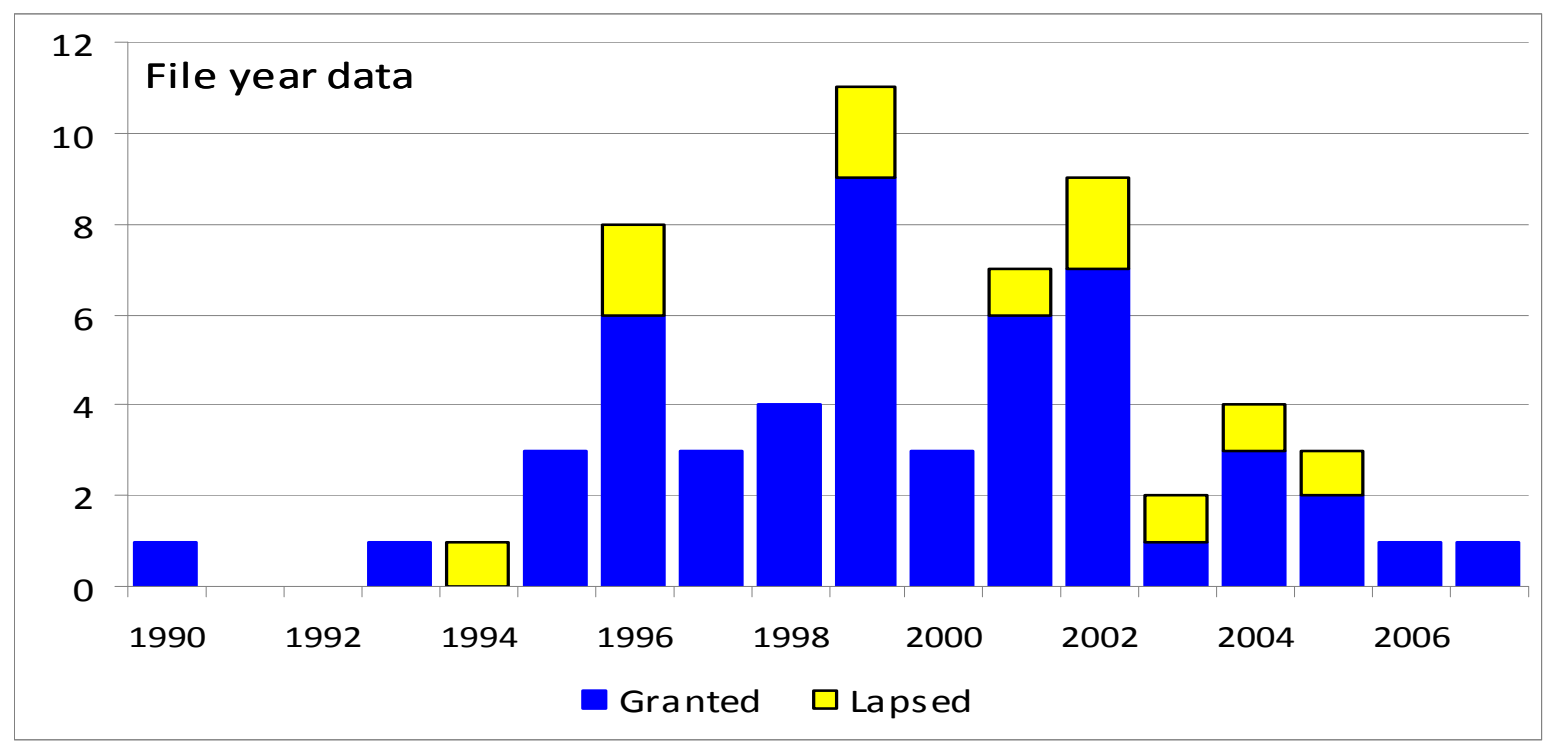

Source: Calculated from data from AusPat.

Many of these patents have been allowed to cease. As at mid 2013 there were 12 alendronic acid evergreening patents still in force. Of the 51 evergreening patents only one has been challenged in court.

In 2004 Arrow Pharmaceuticals challenged patent 2000064069 (741818), "method for inhibiting bone resorption". Interestingly Merck did not counter-claim for infringement. The challenged claims covered methods of treatment and alendronate compositions. The Federal Court was scathing about both. ${ }^{112}$ In respect of the method of treatment claims it said:

"... I would hold that each of the so-called method [of treatment] claims was one way of utilising alendronate and its known qualities for the known purpose of preventing or treating osteoporosis by a known method of oral administration. They are in the nature of directions for use. That does not constitute an invention..."

In regard to the composition claims the Court said:

"There is nothing that is claimed to be new or novel with any utility about the carrier, the active ingredient, or the quantity or the method by which the ingredients are 'composed'. Reference is only made to standard mixing and formulation techniques. In particular, there is no practical meaning or substance to the statement that the composition is 'adapted for oral administration as a unit dosage according to a continuous schedule having a periodicity of about once weekly'. ...These are not composition claims as that concept would normally be understood, that is, claims to a new and unique compound. They are not combination claims whereby the whole is something different from the sum of the parts. When properly analysed the composition claims are devoid of practical content. They are not 'inventions' ..."

The Full Court upheld the patent revocation and the High Court refused leave to appeal. The whole legal process took some two and a half years.

\footnotetext{
${ }^{112}$ Arrow Pharmaceuticals v Merck [2004] FCA 1282.
} 
Figure 13 Alendronate

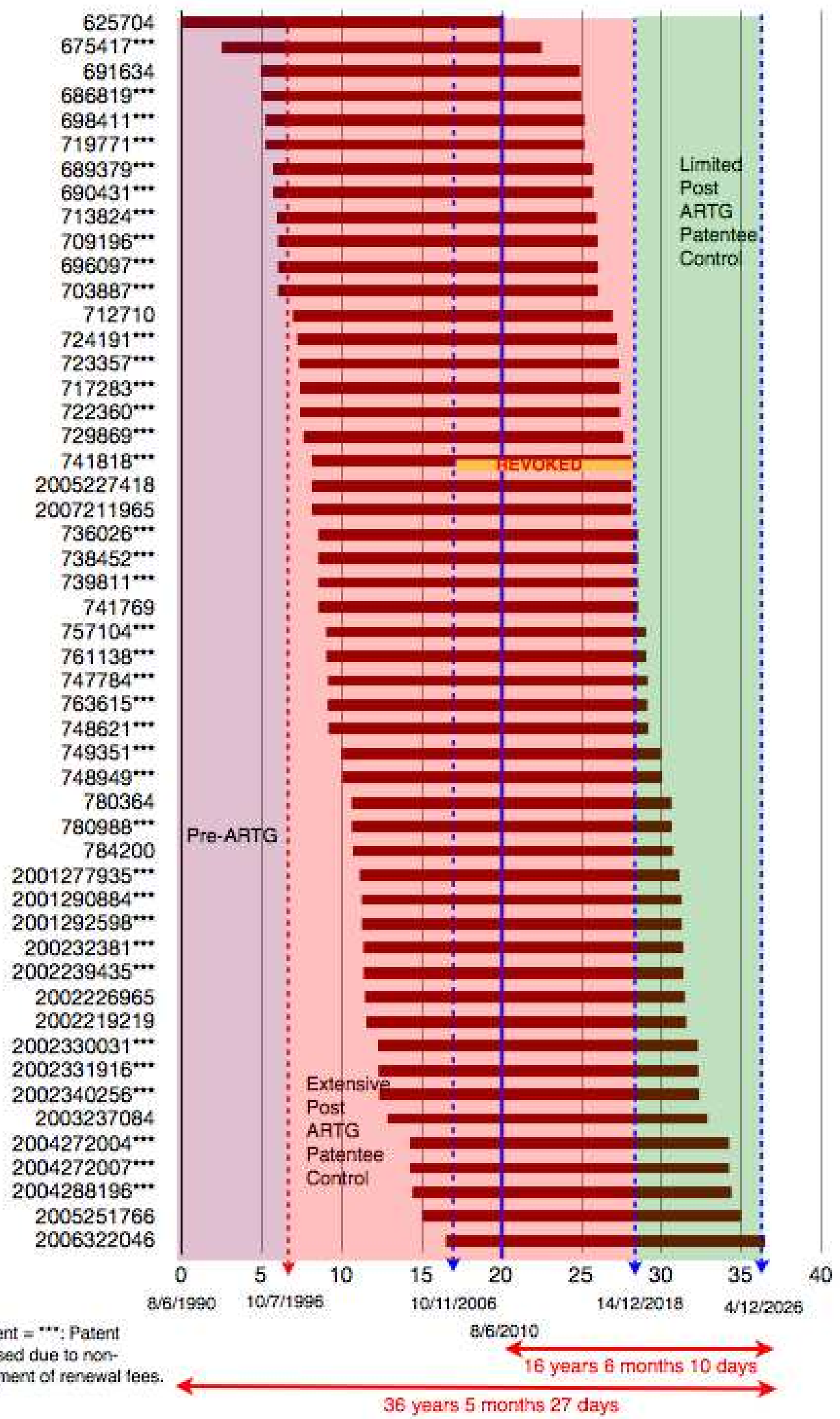

Source: Calculated from data from AusPat and the ARTG. 
The revocation of this patent allowed generic entry and several generic forms were approved by the ARTG in late May 2005. ${ }^{113}$ At present the PBS lists two item codes for pure alendronate, a 40mg version where the only listing is for FOSAMAX and a 70mg once-a-week version where there are 11 approved generic brands. For the combination of alendronate and vitamin $D_{3}$ the PBS shows four different code items but there is generic competition for only one of these. ${ }^{114}$ For FoSAMAX PLUS D-CAL there are two code items but the only listed brands are from Merck. Clearly there is very limited generic competition in the combination alendronate products, though these are taking an increasing share of the total market. Since generic entry of simple alendronate in mid 2005, its share of total alendronate product revenues has decreased to 22 per cent in 2012-13 (see Figure 14). Thus while generics now have almost the whole market for pure alendronate, there is limited generic presence in the now far larger market (by value) for combined alendronate products.

Figure 14: Changing share of alendronate market by volume

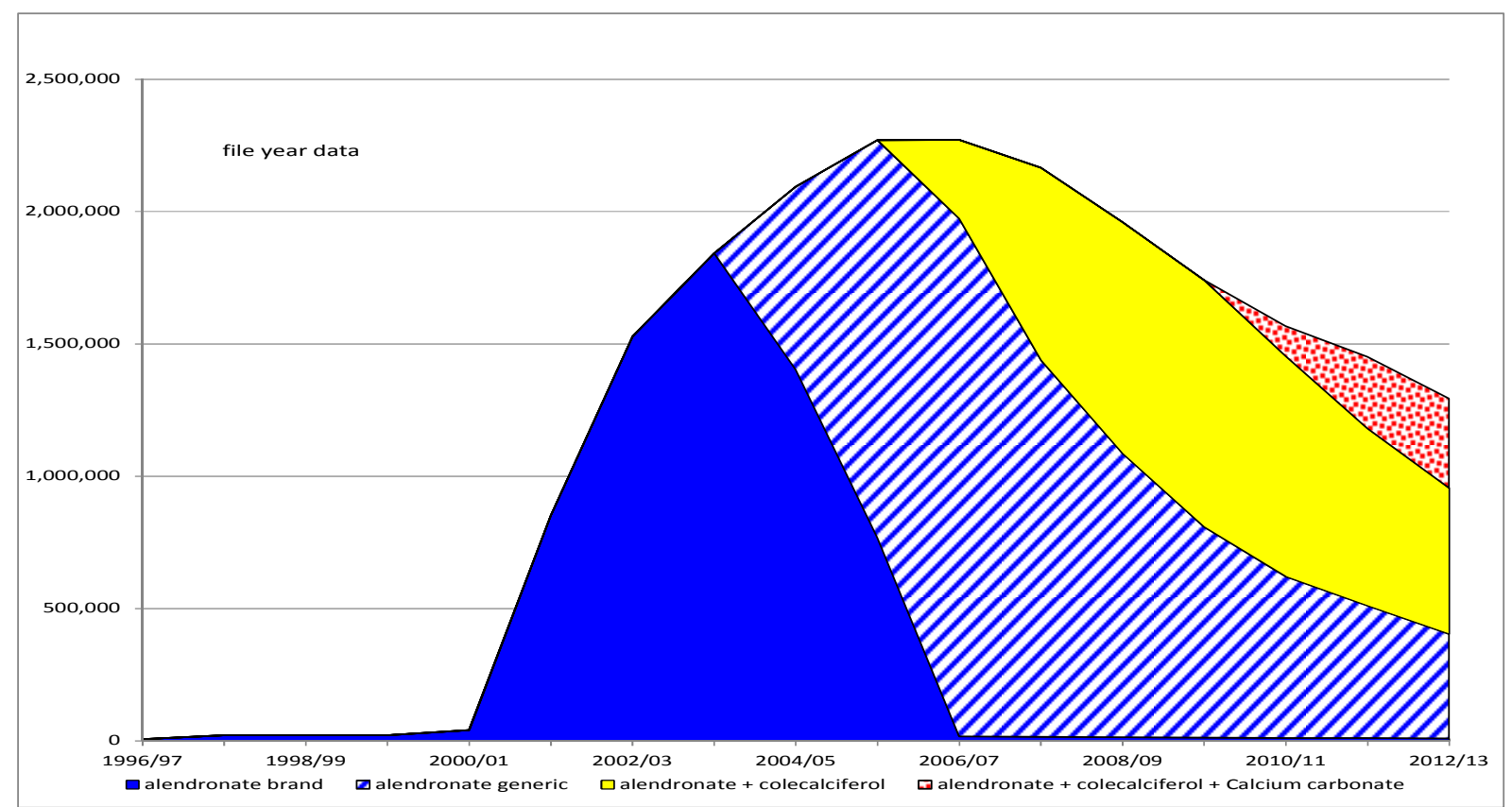

Source: Calculated from data available at https://www.medicareaustralia.gov.au/statistics/pbs item.shtml. Assumes that generics took three years from mid 2005 to fully enter the market.

The last of the Fosamax patents is not due to expire until December 2026. Other patents still in force include two treatment method patents not due to expire until 17 July 2018. These treatment patents are directly linked to the revoked patent. The revoked patent had a divisional - 2002024511 which lapsed before grant - and that had a further divisional 2005227418 - which itself had another divisional - 2007211965. That makes the two current treatment method patents the grand-child and great-grand-child of the patent on which the Federal Court poured such scorn. There are procedures for the Commissioner of Patents to

\footnotetext{
${ }^{113}$ As the Arrow product is called ALENDRO, we searched the ARTG for this product. Three formulations were found (ALENDRO 10mg tablets; ALENDRO $40 \mathrm{mg}$ tablets and ALENDRO once-weekly 70mg tablets) (http://agencysearch.australia.gov.au/s/search.html?query=Alendro\&collection=agencies\&profile=tga, 26 October 2013).

${ }^{114}$ Items 2194L, 2224C and 9012H each show only the single brand Fosamax Plus. Item $9183 \mathrm{H}$ shows a single generic product (supplied by ACTAVIS) and FosAmAX PLUS. There is a brand premium of $\$ 2.49$ payable for the FOSAMAX version of item $9183 \mathrm{H}$.
} 
re-examine patents. Clearly it would be in the public interest for her to have a standard process to re-examine all patents related to a revoked patent.

Given current PBS expenditure on the alendronate plus products, and assuming a 60 to 80 per cent price reduction would be achieved from generic entry, the savings to the taxpayer of reviewing and revoking the remaining evergreening patents would be at least $\$ 0.5$ million a year and could be as much as $\$ 0.74$ million a year. A very good return on a little reexamination.

The alendronate case clearly shows how the strategy of offering "improved" products FOSAMAX Plus instead of FoSAMAX provides a substantial return to the company. In this case the simple combination of a three different bone treatment products (alendronate, calcium and vitamin D) provides a very substantial return to Merck. Merck will have incurred some costs in gaining regulatory approval. It should easily be able to recoup these from the five years of data exclusivity provided by the Australian government. This five-year period ends substantially before the final evergreening patent expires (around 2013-15 compared to 2026). It seems like double-dipping for Merck to be able to acquire a range of trivial patents as well as the data exclusivity restraint on market competition.

\section{G. Risedronate: the role of opposition}

Risedronate, or risedronic acid, is another drug to strengthen bones and treat osteoporosis. It is also used to treat Paget's disease of bone. It was invented by Warner-Chilcott, who own all the Australian patents and two registered trademarks: ACTONEL and ACTONEL E.A.T. COMBI. Seven different versions of this drug have been approved by the ARTG, each with its own variation on the name though these further names are not registered trademarks. The original product, ACTONEL, was trademarked in July 1992, and approved for the market on 14 August 2000. It is supported by an API compound patent filed in December 1985 and granted a 5 year term extension. This gave Warner-Chilcott $10 \frac{1}{3}$ years of effective market exclusivity. Although Warner-Chilcott owns the patents and trademarks, it is marketed in Australia by Sanofi-Aventis.

Like alendronate, risedronate is marketed in three forms: by itself, with calcium carbonate, and with calcium carbonate and colecalciferol (vitamin $D_{3}$ ) each available on the PBS in multiple dosages. ${ }^{115}$ With so many different dosages, there are a total of seven names approved for sale by the ARTG. ${ }^{116}$ There are five dosage options for pure risedronate, with generic competition for two. The most expensive form - a pack of $2830 \mathrm{mg}$ tablets at $\$ A 260$ a script - is available only as ActONEL. All other dosages are in the $\$ 45$ to $\$ 50$ price range. ${ }^{117}$ There is a single generic company competing with ACTONEL for risedronate with calcium carbonate. Interestingly the approved dosage is a small number of risedronate tablets and a larger number of calcium carbonate tablets, simply a co-packaging rather than a genuine combination. There are no generic competitors for the co-packaging of risedronate with a mixture of calcium and vitamin $\mathrm{D}_{3}$.

\footnotetext{
${ }^{115}$ Altogether there are 14 different PBS codes for risedronate and its combinations, though some of these show identical dosages and forms.

${ }^{116}$ In addition to ACTONEL, two other pure risedronate products were approved: ACTONEL ONCE-A-MONTH on 4 March 2009 and ActOnel EC ONCE-A-WeEk (an enteric-coated version) on 10 March 2011. ACtONEL COMBI (risedronate and calcium carbonate) was approved on 12 February 2008. Two versions adding vitamin D to the combination were approved on 10 March 2011 (ACTONEL EC COMBI and ACTONEL EC COMBI D).

${ }^{117}$ Any price above $\$ 36.10$ involves taxpayer subsidy to all final users, not just those on low incomes.
} 
Following the original API patent there was a gap of seven years before the first evergreening patent was filed (Figure 15). This was for a delayed-release form of risedronate. As noted above in the case of venlafaxine, deciding on the appropriate release form for any drug would seem to be a matter of normal procedure. Different release options have been known for many decades. Combining these with any new compound would seem not only obvious but essential. Such combinations do not meet the "significant advance in what is known or used" standard for patent grant advised to the Australian parliament in 2011. Yet they are regularly granted and upheld by the courts.

Nine years later the second and third evergreening patents were filed, both for compounds and manufacturing processes. A method of treatment "invention" was filed in 2002. Three applications were filed in 2004 and all were accepted for grant. However two generic companies opposed the grant of the 2004322703 "invention" for a product and method of treatment. Warner-Chilcott then actively withdrew the application. Two further patents filed in 2005 were accepted for grant. One was the divisional child of the other and it (2005330654) was opposed in 2011 by the generic company Apotex. The opposition procedures had not been resolved as at 25 October 2013. The opposed patent claims that dosage forms of risedronate combined with a chelating (binding) agent in a delayed release form will overcome problems with the interaction of risedronate with food or drink to achieve greater compliance. A further application in 2008 - also a divisional child of the granted 2005 patent has very similar claims. It was granted without query despite the opposition procedures regarding its sibling. This set of three closely similar applications pushes the final patent expiry date out to 14 April 2025 - over 39 years since the original patent filing, and nearly 25 years after first ARTG approval.

Figure $15 \quad$ Risedronate: original and evergreening patents and applications

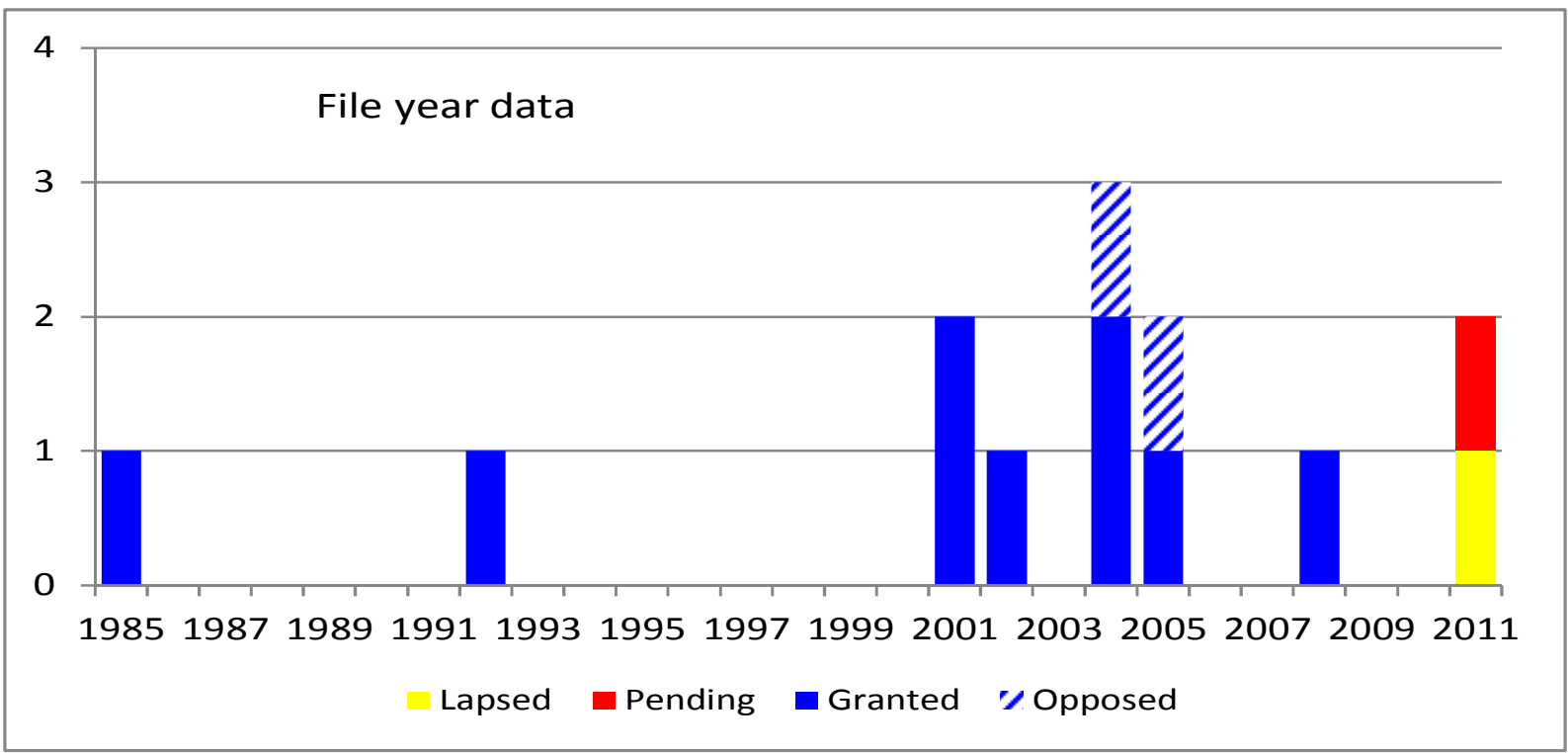

Source: Calculated from data from AusPat.

Not satisfied with this Warner-Chilcott filed another two applications in 2011. One (application 2011218625) has an effective date of 14 May 2005 rather than the file date of 29 August 2011. It is a child of the currently opposed patent which is itself a child of granted patent 2005247299. The initial examiner's report on this application raised both novelty and inventiveness problems. Warner-Chilcott redrafted the claims - with the number of claims increasing from 10 to 30 - and the patent is now accepted pending the completion of 
formalities. This last patent will not extend the period of protection beyond 14 April 2025 but will make generic competition on specific dosages, compositions and methods of treatment more challenging.

Risedronate and alendronate treat similar medical problems and are sold jointly with other products which play a role in strengthening bones - calcium carbonate and vitamin D. Both involve additional patents which substantially extend the period during which generic competition is excluded. Both sets of patents show problems identified in earlier cases: patenting specific release formulations and patenting combinations of known compounds.

\section{H. Cefuroxime: and how many term extensions}

This antibiotic is used to treat bacterial infections, including respiratory tract infections, middle ear infection and pneumonia. This second-generation cephalosporin antibiotic is particularly used for patients who are allergic to amoxicillin. ${ }^{118}$ FORTUM (cefuroxime pentahydrate) was approved for marketing on 27 March 1986 and ZINNAT (cefuroxime axetil) on 21 December 1993. Cefuroxime axetil is a derivative form of cefuroxime, an ester. The original API application was filed in April 1979, claiming processes of manufacture, specific compositions and the compound. The patent ran for 16 years to April 1995. Glaxo followed this original application with a further 24 evergreening patents, including one innovation patent. Only one application was allowed to lapse before grant. At least in Australia ZINNAT has completely replaced FORTUM on the market - FORTUM is no longer listed on the PBS. As a consequence we are unable to identify the switch between FORTUM and ZINNAT.

The interesting thing about this case is that Glaxo managed to achieve term extensions on no less than four of these evergreening patents, despite having market approval for only two brand products. The data in Table 3 show that Glaxo achieved a substantial term extension for each version of cefuroxime. In 1990 Glaxo was successful in its challenge to the USPTO's refusal of a term extensions for cefuroxime axetil (on the grounds that this was not the first marketed cefuroxime product). The CAFC overturned the USPTO decision, taking a much narrower approach to defining a relevant commercially marketed product. ${ }^{119}$

But even if it is argued that parliaments intended such a narrow approach to defining relevant products for patent term extensions, the question remains as to why the two shorter term extensions were granted in Australia. Why were improvements to cefuroxime given a nearly six month extension? And why was a coated tablet form also given a nearly 10 month extension?

Two dosages of ZINNAT are currently listed on the PBS - a tablet form and a powder form. While there are generic versions on the US market, ${ }^{120}$ there is no generic competition in Australia, although only one patent remains in force. This patent, 2002302147 for a "pharmaceutical composition" does not expire until 21 November 2022. The abstract describes this "invention" as a particulate form of cefuroxime axetil where the particles are coated with a water-insoluble lipid mixture, including a sweetener and a texture modifier, serving to mask the bitter taste. None of these patents have been challenged in court. There

\footnotetext{
118

http://www.nps.org.au/medicines/infections-and-infestations/antibiotic-medicines/antibiotics-forrespiratory-tract-infections/for-individuals/active-ingredients/cefuroxime (5 October 2013).

${ }^{119}$ The CAFC held that the earlier commercial marketing of salts of cefuroxime was not relevant to the request for a term extension for the ester of cefuroxime (see Kotze 2012: 1438-1440, citing Glaxo, 894 F.2d at 394).

120 http://www.wikinvest.com/stock/GlaxoSmithKline \%28GSK\%29/Pharmaceuticals Competition (5 October 2013).
} 
may be little incentive for generic entry - the current (2013) prices for ZINNAT are below $\$ A 20$. As there is an automatic 16 per cent price fall on generic entry, this is clearly a far less attractive market than higher-priced drugs.

Table $3 \quad$ Merck's cefuroxime term extensions

\begin{tabular}{|l|l|l|l|l|}
\hline Application \# & Title & Type of claims & Expiry date & $\begin{array}{l}\text { Term } \\
\text { extension }\end{array}$ \\
\hline $\begin{array}{l}\text { 1979047422 } \\
\text { [FORTUM] }\end{array}$ & Cephalosporin antibiotics & $\begin{array}{l}\text { process, composition } \\
\text { and compound }\end{array}$ & 25 May 1999 & 4 years \\
\hline 1980062882 & $\begin{array}{l}\text { Improvements in or relating } \\
\text { to cephalosporins }\end{array}$ & $\begin{array}{l}\text { process, composition } \\
\text { and compound }\end{array}$ & 27 Mar 2001 & $\begin{array}{l}5 \text { months, } \\
27 \text { days }\end{array}$ \\
\hline [ZINNAT] & $\begin{array}{l}\text { Novel form of cefuroxime } \\
\text { ester, process for its } \\
\text { preparation and } \\
\text { composition containing it }\end{array}$ & compound & Jul 29, 2007 & 5 years \\
\hline 1986063232 & $\begin{array}{l}\text { Coated cefuroxime axetil } \\
\text { tablets }\end{array}$ & process and product & 21 July 2007 & $\begin{array}{l}9 \text { months, } \\
22 \text { days }\end{array}$ \\
\hline
\end{tabular}

The pattern to patenting new cefuroxime "inventions" is unusual, as shown in Figure 16. The original compound application was filed in 1979 and evergreening applications followed immediately, and then again in the period 1983 to 1989. There was then a gap of over 10 years before three further applications were filed. Two of these were granted - the innovation patent, now lapsed, and the composition patent that runs through 2022. Both of these are for sugar-free chewing gum forms of the drug.

Again one has to ask what is the rationale for granting two patents for applying known methods of making sugar-free gum to this known pharmaceutical compound. Once more the removal of the synergy doctrine has substantially undermined the ability of the patent system to grant patents only where there is a significant advance in what is known or used.

\section{Figure 16 Cefuroxime patents and patent applications}

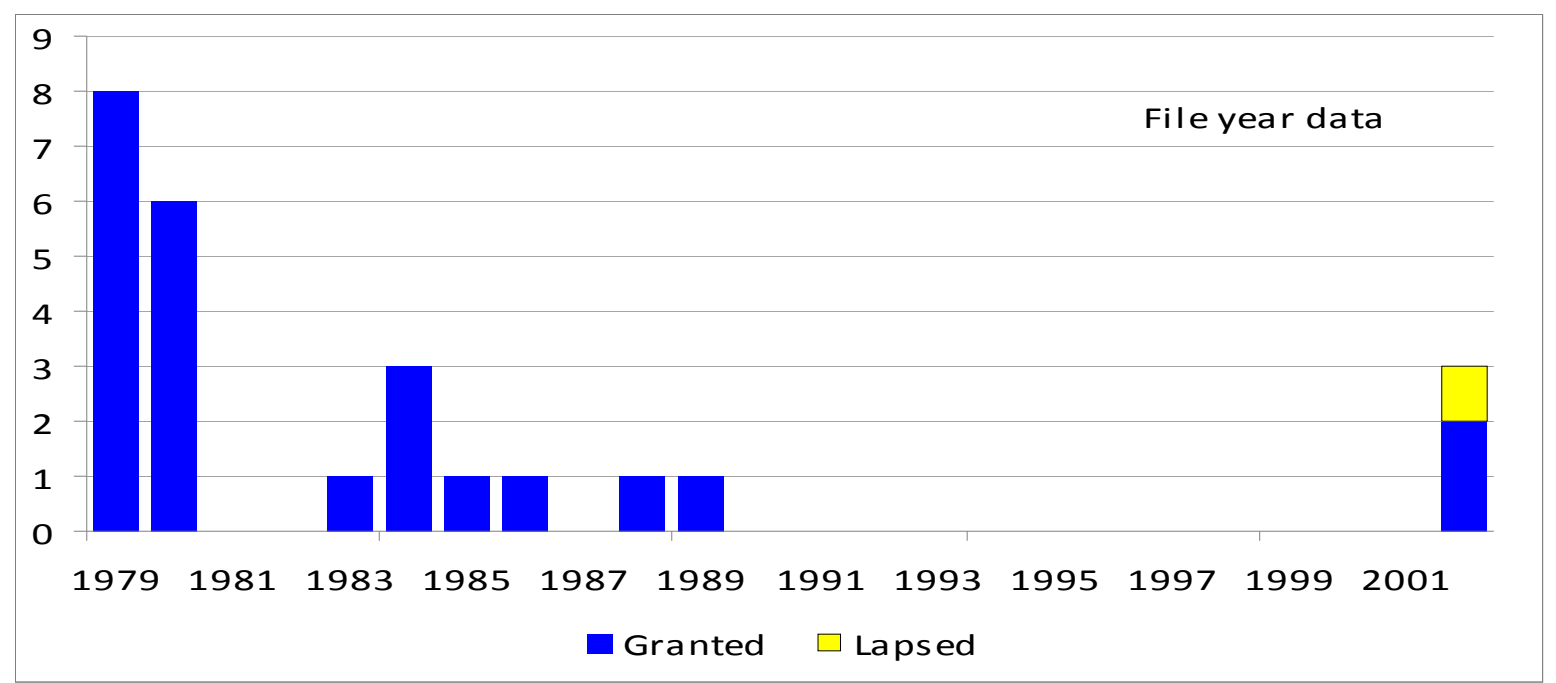

Source: Calculated from data from AusPat. 


\section{Discussion of findings and policy parallels}

These eight cases show that the evergreening of pharmaceutical patent is as well established in Australia as it is in Canada and the USA. It is successful in extending patent protection well beyond the agreed period of 20 to 25 years. The total patent protection sought in the cases discussed here ranges from a minimum of $361 / 2$ years for alendronate to nearly 50 years for LOSEC and NEXIUM (Table 4). The patent protection period prevents others from competing to develop any commercial products or uses of the protected compound. But evergreening patents for variants of the compound, processes for manufacture and methods of treatment including specific dosages and delivery forms also operate to prevent competition when the original patent has expired.

Commercial returns are dependent on the period of effective market life - from market approval to entry of generic competitors. Generic competition usually leads to price falls of the order of 60 to 80 per cent - in one of our cases prices for a blockbuster drug fell by 90 per cent on generic entry. The average length of effective market life in the USA is 12 years (Hemphill and Sampat 2012). In two cases in the dataset the original period of market exclusivity fell far short of this - there was no exclusive period for CIPRAMIL (citalopram) and there was only four years for PLAVIX (clopidogrel). In both cases the originator companies were able to substantially extend market exclusivity. Lundbeck is effectively seeking 27.5 years for es/citalopram and Sanofi is seeking 14.2 years for PLAVIX. ${ }^{121}$ Other companies have been more ambitious, with Astra seeking over 38 years for LOSEC and its enantiomer NEXIUM; Glaxo seeking over 36 years for two forms of cefuroxime (FORTUM and ZINNAT); and Merck seeking over 31 years for FoSAMAX (alendronate).

For a number of cases we have been able to estimate the cost to the taxpayer where generic entry is delayed by patents over quite small "improvements" (see table 4). The High Court upheld a patent for an "invention" that combined a known compound (omeprazole) with a known process for controlling delivery - an enteric coating - overriding the decisions reached by lower courts. This was an expensive judgement for Australian taxpayers, resulting in the transfer of some $\$ A 607$ million to AstraZeneca. A later judgement by the Federal Court that an extended release formulation of venlafaxine was not valid saved taxpayers some \$A209 million (provided, that is, that the Department of Health takes action to recover these monies). Upholding the enantiomer patent for citalopram cost taxpayers some $\$ A 47$ to 62 million (which will rise to $\$ A 123$ to 164 million if the disputed term extension is granted).

We have not been able to estimate the cost to generic firms of being excluded from pharmaceutical markets for longer than the period agreed by government, i.e. the period covered by the genuinely inventive original API patent. However losses to Australian taxpayers give some indication of the orders of magnitude of the markets from which generics are being wrongly excluded.

\footnotetext{
${ }^{121}$ Sanofi attempted to extend market exclusivity further - to 23.2 years for the combination of clopidogrel with aspirin. This was unsuccessful as the supporting patent was challenged and revoked.
} 


\section{Table 4 Summary findings}

\begin{tabular}{|c|c|c|c|c|c|c|c|c|c|c|c|}
\hline \multirow{2}{*}{$\begin{array}{l}\text { Drug } \\
\text { INN }\end{array}$} & \multicolumn{3}{|c|}{$\begin{array}{c}\text { Length of patent protection } \\
\text { (years) }\end{array}$} & \multicolumn{3}{|c|}{ Market exclusivity period ${ }^{a}$} & \multirow{2}{*}{$\begin{array}{c}\# \\
\text { evergreen } \\
\text { grants } \\
\end{array}$} & \multicolumn{2}{|c|}{ Nature of blocking patent } & \multicolumn{2}{|c|}{ Estimated cost to taxpayer (\$Am) } \\
\hline & $\begin{array}{c}\text { original } \\
\text { API }^{b}\end{array}$ & $\begin{array}{l}\text { intermediate } \\
\text { evergreen }\end{array}$ & \begin{tabular}{c|} 
last \\
evergreen
\end{tabular} & $\begin{array}{c}\text { original } \\
\text { API }^{b}\end{array}$ & $\begin{array}{c}\text { intermediate } \\
\text { evergreen }\end{array}$ & \begin{tabular}{c|c} 
last \\
evergreen
\end{tabular} & & $\begin{array}{c}\text { intermediate } \\
\text { evergreen }\end{array}$ & $\begin{array}{c}\text { last } \\
\text { evergreen }\end{array}$ & $\begin{array}{l}\text { intermediate } \\
\text { evergreen }\end{array}$ & last evergreen \\
\hline $\begin{array}{l}\text { Venlafaxine }(+ \\
\text { desvenlafaxine) }\end{array}$ & 25.0 & $33.3^{c}$ & $39.7^{d}$ & 14.1 & $22.3^{\mathrm{C}}$ & $28.8^{d}$ & 7 & $\begin{array}{c}\mathrm{XR} \\
\text { formulation } \\
\end{array}$ & metabolite & 209 & 45 to 76 \\
\hline $\begin{array}{l}\text { Citalopram / } \\
\text { escitalopram }\end{array}$ & 16.0 & $32.4^{\mathrm{e}}$ & $49.3^{f}$ & -ve & $\begin{array}{r}11.5 \\
(16.5)^{\mathrm{g}} \\
\end{array}$ & 28.4 & 39 & enantiomer & $\begin{array}{l}\text { treatment } \\
\text { method }\end{array}$ & $\begin{array}{r}47 \text { to } 62^{\mathrm{e}} \\
(123 \text { to } 164) \\
\end{array}$ & 76 to $102^{f}$ \\
\hline Clopidogrel & 20.0 & & 29.6 & 4.1 & & 14.2 & 12 & & enantiomer & & $\begin{array}{r}60 \text { plus } \\
480-600\end{array}$ \\
\hline $\begin{array}{l}\text { clopidogrel } \\
\text { with aspirin }\end{array}$ & & & $(38.6)^{h}$ & & & $(23.2)^{h}$ & & & $\begin{array}{l}\text { combined } \\
\text { compounds }\end{array}$ & & na \\
\hline $\begin{array}{l}\text { Omeprazole/ } \\
\text { esomeprazole }\end{array}$ & 20.0 & $28.0^{j}$ & 48.1 & 10.4 & $18.4^{j}$ & 38.4 & 61 & $\begin{array}{c}\text { enteric } \\
\text { formulation }\end{array}$ & enantiomer & 607 & \\
\hline Atorvastatin & 25.0 & 25.4 & 37.0 & 15.4 & 15.8 & 24.0 & 14 & compound & $\begin{array}{l}\text { process / } \\
\text { product }\end{array}$ & na & na \\
\hline $\begin{array}{l}\text { atorvastatin } \\
\text { \& amlodipine }\end{array}$ & 20.0 & & & $11.4^{k}$ & & & & & & na & na \\
\hline Alendronate & 20.0 & $28.1^{m}$ & 36.5 & 14.9 & $23.0^{\mathrm{m}}$ & 31.4 & 51 & & & & \\
\hline Risedronate & 25.0 & 26.9 & 39.3 & 10.4 & 12.2 & 24.7 & 10 & & & & \\
\hline Cefuroxime & 16.0 & 20.1 & 43.6 & 9.0 & 13.2 & 36.6 & 24 & & & na & na \\
\hline
\end{tabular}

a From first ARTG approval to expiry of last identified patent

b For alendronate this is the first evergreening patent as original compound never patented in Australia.

c extended release formulation patent

d desvenlafaxine patent

e enantiomer patent; term extension currently being disputed

f $\quad$ last evergreen patent (manufacturing process) $\mathrm{g} \quad$ if new term extension application upheld

$\mathrm{h} \quad$ this hoped for term was not achieved as the patent was revoked.

j enteric coating patent (upheld by High Court)

$k$ from ARTG approval for CADUET (atorvastatin plus amlodipine)

m revoked patent application 2000064069 for compositions and methods of treatment. 
The case studies have also thrown more light on a variety of patterns to evergreening:

- $\quad$ while vast numbers of patents create an expensive thicket to work through, a small number of carefully selected patents can be highly effective in delaying generic market entry

- this effect is particularly strong when brand companies spend heavily on "educating" prescribers about the "advantages" of replacement products (for example EFEXOR, EFEXOR-XR and PrISTIQ; LOSEC and NeXIUM; CIPRAMIL and LeXAPro);

- the patenting of variants of compounds has a strong negative effective on generic entry. Evergreening would be much reduced - to the substantial benefit of Australian taxpayers and the greater health of the Australian generic pharmaceuticals industry if patenting standards were raised to exclude patents for:

- $\quad$ enantiomers if the racemic mix has already been patented (and vice versa);

- $\quad$ salts, esters, ethers, polymorphs, metabolites etc

- $\quad$ new delivery forms for known compounds if that delivery form is already known;

- combinations of known compounds; and

- $\quad$ methods of using already patented compounds

- marketing is highly effective in persuading decision-makers to switch to more expensive forms of known drugs even where these offer no therapeutic advantage.

\section{Variant compounds}

The case material presented here has provided several examples of companies trying to extend their exclusive market period by patenting both racemic mixtures and enantiomers. There has been a recent shift in Australian patent law in this regard. Following two divergent decisions (from the same three judges) the Patent Office has revised its guidelines to indicate that enantiomers will usually not meet patentability standards. This aligns with the opinion of Justice Emmett who considers that as any racemic compound inevitably discloses the component enantiomers, such applications do not pass the novelty standard. In September 2012 the patent office revised its guidelines to state that enantiomer patents would not normally be granted. It does not yet seem to have moved to re-examine those enantiomer patents which were granted before it clarified its guidelines, such as those over esomeprazole.

Other minor variations on the originally patented compound readily pass the very low standards for patentability in Australia. Desvenlafaxine is the major metabolite of venlafaxine and has an identical therapeutic effect yet was granted a patent in its own right and even a term extension. One of the cefuroxime patents (ZINNAT) is for an ester of the other (FORTUM). Both were granted patents.

There is substantial global concern about the health impact of such low standards of patentability. ${ }^{122}$ In proposing patentability standards for pharmaceuticals to the World Health Organization (WHO) and United Nations Conference on Trade and Development (UNCTAD), Correa recommends, for example, that:

"New formulations and compositions, as well as processes for their preparation, should generally be deemed obvious ... particularly when a single active ingredient is claimed in association with known or unspecified carriers or excipients." (Correa 2007: 7)

\footnotetext{
${ }^{122}$ As Gleeson and colleagues point out in their useful review of the impact of the proposed (secret, but leaked) Annex to the proposed (secret) Transparency chapter of the proposed TPPA, increased prices for health care products reduce access to health for more vulnerable groups in society (Gleeson et al. 2013: 5-6).
} 
After the packaging of the TRIPS Treaty with GATT, India was obliged to amend its patent law to provide pharmaceutical patents. ${ }^{123}$ In addition to the normal threshold requirements of inventiveness and industrial application, the amended law codified non-patentable inventions. Section 3 (d) specifies that a non-patentable invention includes:

"the mere discovery of a new form of a known substance which does not result in the enhancement of the known efficacy of that substance or the mere discovery of any new property or new use for a known substance or of the mere use of a known process, machine or apparatus unless such known process results in a new product or employs at least one new reactant.

Explanation.-For the purposes of this clause, salts, esters, ethers, polymorphs, metabolites, pure form, particle size, isomers, mixtures of isomers, complexes, combinations and other derivatives of known substance shall be considered to be the same substance, unless they differ significantly in properties with regard to efficacy."

During a recent case the Indian Supreme Court considered this clause in detail, and cited evidence provided by Professor Basher that the wording of section 3(d) originated from a 2004 European Drug Regulatory Directive. ${ }^{124}$ While this Directive is directed to the approval of pharmaceuticals for sale, the view that these variants require no additional regulatory approval unless "they differ significantly in properties with regard to safety and/or efficacy" suggests that this should be at least a minimum standard for grant of secondary pharmaceutical patents. At present it is not.

\section{Combinations of known things}

A further finding from the case studies is that combinations of known things also qualify for further patents. Although alternative methods of delivering drugs - for example immediate, delayed or extended release - have been well-known for decades, the patent system considers that combining such well-known techniques with each different compound qualifies for a further patent. To the citizen who pays for this, there is a presumption that drug companies will actively consider the best method of delivering each drug and ensure that this occurs as a matter of standard practice. Our cases include a patent for an extended release form of venlafaxine that successfully kept competitors out of the market for $2 \frac{1}{2}$ years before it was revoked. The High Court upheld the use of an enteric coating on omeprazole (LOSEC) as sufficiently inventive to qualify for a patent. This decision has been

\footnotetext{
${ }^{123}$ During the early decades of independence India undertook substantial work assessing what kind of patent law best suited it before revising the statute inherited from the UK. Under this new (1970) law patents could not be granted for pharmaceuticals. India was not alone in this policy approach - before the adoption of the European Patent Convention in the 1970s many European countries did not grant patents for inventions relating to food or medicines. At the time the TRIPS Agreement became part of the WTO package of treaties more than 50 countries did not provide patents for pharmaceutical products.

${ }^{124}$ Novartis AG v Union of India and others, Civil Appeal Nos. 2706-2716 of 2013, Supreme Court of India at 185. Directive 2004/27/EC defines a generic medical product as "a medicinal product which has the same qualitative and quantitative composition in active substances and the same pharmaceutical form as the reference medicinal product, and whose bioequivalence with the reference medicinal product has been demonstrated by appropriate bioavailability studies. The different salts, esters, isomers, mixtures of isomers, complexes or derivatives of an active substance shall be considered to be the same active substance, unless they differ significantly in properties with regard to safety and/or efficacy. In such cases, additional information providing proof of the safety and/or efficacy of the various salts, esters or derivatives of an authorized active substance must be supplied by the applicant." (Article 10(2)(b) at http://ec.europa.eu/health/files/eudralex/vol1/dir_2004_27/dir_2004_27_en.pdf).
} 
considered as totally removing the inventiveness requirement from the Australian patent system (Lawson 2008). It also delayed generic entry into the market for this expensive drug by eight years at an estimated cost to the Australian taxpayer of $\$ A 728$ million.

Two of our cases illustrate another aspect of policy that requires patents - powerful exclusive rights - to be granted for combinations of known things. Patents were granted for the combination of clopidogrel and aspirin; and for the combination of atorvastatin and amlodipine; and for the combination of each of alendronate and risedronate with calcium and vitamin D. The patent combining clopidogrel with aspirin was seen as so weak by its owner, Sanofi, that when it was challenged they did not bother to defend it. Yet this obvious combination was granted a patent and Sanofi used this to acquire an unjustified 2.7 years of market exclusivity. The combination of atorvastatin and amlodipine has not yet been challenged. Nor have the patents for combinations of alendronate or risedronate with calcium and vitamin $\mathrm{D}$. There are substantial biases against challenging even the most obviously invalid patents - the party challenging validity bears all costs and risks yet shares benefits with all competitors as soon as a patent is revoked.

\section{Are there health improvements?}

Large pharmaceutical companies argue that these kinds of variations to their original compound provide improvements in health outcomes and that this justifies the grant of both patents and data exclusivity privileges.

It is well-known that one enantiomer can hold the full therapeutic effect of a racemic mixture. In practice this means that one of these closely related forms can have a better therapeutic effect than the other. But the discovery of a compound with a chiral centre automatically discloses the knowledge regarding the enantiomers. There is no rational argument for granting two patents for a single invention, especially when these patents are sought back-to-back rather than simultaneously.

Other variations on an original compound - in the form of salts, esters, metabolites, polymorphs and so on - often have an identical therapeutic effect as we have seen in the case of desvenlafaxine. The same is true for cefuroxime where an evergreening patent (2002302147) ensures that ZINNAT is the only cefuroxime medicine available on the PBS some 18 years after the original compound patent expired. ${ }^{125}$ As noted above the 2004 European Drug Regulatory Directive states that such forms require no additional regulatory approval unless "they differ significantly in properties with regard to safety and/or efficacy." In the case of desvenlafaxine Pfizer undertook 10 new Phase III trials, involving over 3,500 clinically depressed people, some of whom were given a placebo. ${ }^{126}$ As it emerged the drug has an identical therapeutic effect to venlafaxine. This raises some challenging questions about the Phase III trials which Pfizer undertook.

Firstly, far from the cost of such trials supporting an argument for patent protection to recoup their cost, the question is what lack of protection led to so many vulnerable people being exposed to known inferior medical treatment (placebos)? Secondly, why did the two

125 http://www.nps.org.au/medicines/infections-and-infestations/antibiotic-medicines/antibiotics-forrespiratory-tract-infections/for-individuals/active-ingredients/cefuroxime/for-individuals/brands-of-cefuroxime

126 European Medicines Agency, Withdrawal Assessment Report for Ellefore, International Non-proprietary

Name: DESVENLAFAXINE Procedure No. EMEA/H/C/932, pp 13-14 (available at http://www.ema.europa.eu/docs/en GB/document library/Application withdrawal assessment report/2010 /01/WC500064246.pdf). 
trials using both venlafaxine and desvenlafaxine not compare the efficacy of the two products? Thirdly, how is Pfizer able to claim that desvenlafaxine is more effective than venlafaxine when it has specifically avoided undertaking the necessary research? Is this not deceptive advertising? Fourthly, given that the sole beneficiary of the production of desvenlafaxine is Pfizer, what regulatory systems are needed to prevent clinical trials that are motivated solely by profit and provide no therapeutic benefit? Finally, why do patent offices and health authorities encourage such behaviour by granting patents and purchasing the resultant unnecessary product?

Other cases in our study include combinations of known things which have a clear, though minor, health advantage. Good examples are extended-release venlafaxine and enteric coated omeprazole. Alternative forms of delivery mechanism (immediate, extended-release or delayed) have been well known since the 1960s, suggesting that their selection for use with any new API is routine not inventive. Nonetheless clinical trials may have been necessary to obtain marketing authority for EFEXOR-XR and enteric LOSEC. Pharmaceutical companies have successfully persuaded the trading nations of the world that to be a member of the World Trade Organization (WTO) countries must provide a period of 5 years data exclusivity during which Phase III clinical trial data cannot be used to support generic market entry. Given this effective subsidy of the clinical trials, further subsidies should not be needed to induce such small improvements. It is not necessary to compromise the goals of the patent system by forcing the provision of patents for combinations of known things and processes.

Other secondary patents involve presentations (tablet or capsule forms), combinations with other APIs, different inert ingredients or alternative formulations such as sugar-free gum. All these improvements cost far less to develop than the original API, especially where only limited (if any) trials are needed. The science behind all these variations on the theme is well understood. The economic need for patents on these sequential developments is, in many instances, highly questionable.

\section{Methods of medical treatment}

One possible explanation for the many evergreening patents directed to methods of treatments is the 1992 Full Federal Court decision which overturned the long-standing view that methods of medical treatment were not patentable. ${ }^{127}$ The case concerned the patentability of a method to treat sleep apnoea. The Full Federal Court, two to one, upheld its validity. Justice Lockhart observed that "the Parliament had the opportunity to exclude methods of treating the human body when it enacted the 1990 Act but the limit of the exclusion was s. 18(2), namely: "human beings, and the biological processes for their generation, are not patentable inventions"'". Justice Wilcox, concurring, noted:

"... that in the face of apparently deliberate decisions by Parliament not to build this particular exclusion into its legislation, courts should be hesitant to introduce the exclusion by reference to those very general principles."

Justice Sheppard, dissenting, believed that it was "not going too far" for a court to consider whether the grant of a patent was appropriate in circumstances where the exercise of a patent owner's exclusive patent rights over the use of an invention "might mean the death

\footnotetext{
${ }^{127}$ Anaesthetic Supplies Pty Ltd v Rescare Ltd (1992) 25 IPR 119.
} 
or unnecessary suffering of countless people". Having examined the technology and the human disease, which he described as "life threatening", he held the patent invalid.

The statements by the two judges handing down the majority opinion profoundly misunderstand the workings of parliament. The Patents Bill 1990 had bi-partisan support. In its original form, and based on acceptance of recommendations from the review committee (IPAC 1984), no exclusions to patentability were specified. It was generally held that traditional exclusions - including the traditional exclusion of methods of medical treatment would remain in place. Nothing in the documents associated with the bill nor the debates surrounding its passage suggests otherwise. But the government of the day did not hold the majority in the Senate and independent Tasmanian Senator Harradine traded an amendment for support on other legislation. The government thus included one specific subject matter exclusion in the final Bill. This indicated no parliamentary intent to remove the range of existing subject matter exclusions, including algorithms, mental models (business processes) and methods of medical treatment.

Furthermore one can question why it is necessary for companies to seek - and governments to grant - patents over specific uses of a compound when a patent has already been granted over that compound. The compound patent provides a powerful exclusive right - the right to exclude any other party from any commercial use of the compound during the term of the patent. There is simply no need for evergreening patents covering methods of medical treatment.

\section{Marketing}

As noted by the European Commission, brand pharmaceutical companies spend a higher proportion of revenue on marketing than on R\&D. In most countries government regulations prevent direct-to-consumer marketing of pharmaceuticals (currently only permitted in the USA and New Zealand) as there is a body of evidence that such advertising causes greater harm than benefit. The $2011 \mathrm{draft}$ Annex to the TPPA Transparency chapter proposes making such advertising obligatory (Gleeson et al. 2013: 5).

Our case studies show how brand pharmaceutical companies use their large marketing budgets to achieve prescribing switches between virtually identical products. Such changes in prescribing offer no therapeutic benefit but do lead to large transfers from taxpayers to these global companies.

Clearly there is a strong case for reducing such perverse outcomes. Tightening patentability standards would remove the capacity for these companies to seek a second bite at the cherry when they have already had a full 25 years of patent protection for a particular API. It would also be in the public interest to limit the access these companies have to decisionmakers in the prescribing system.

\section{Using patent data for policy analysis}

While it is often said (by patent offices) that patent data are an invaluable source of information on leading-edge technology, those who have considered patent databases from a user perspective are well aware that they are mostly of value only to would-be applicants. Is it possible to develop a complete and reliable set of data on the pharmaceutical patents covering any specific API by structured searching of official databases? While the patents identified in the case studies are all on the Australian patents register and are searchable electronically, finding all of the patents that were relevant or related to each of the branded 
medicines was not straightforward. Indeed, it was time consuming, tedious and expensive in terms of both the high level of expertise required to be held by patent searchers undertaking the search and the time taken for them to identify all such patents. In comparison with data extracted by an experienced patent attorney, key-word searching of titles, abstracts or even complete specifications can fail to identify relevant patents. The constantly changing ownership structures in the global pharmaceutical industry impede using applicant name as an alternate approach to identifying such patents. The paper presents detailed data for five cases comparing the outcomes of structured keyword searches with data extracted by an experienced patent attorney. These data show that critical patents are missed in structured searching, particularly the original API patent and secondary patents filed early in the life of the main API patent.

\section{Innovation patents}

The study also reveals that Australia's second tier patent system - the innovation patent - is also used in the process of evergreening branded medicines. An innovation patent can be quickly granted as a divisional while the standard patent application upon which it based proceeds through a much longer period of examination. As innovation patents are subject to an expedited examination process they are granted more quickly than a standard patent. They can therefore be enforced through the Australian courts while the standard parent patent application (still being examined) has not yet been granted. Indeed, there is no legal requirement that a standard patent ever be granted. The grant of preliminary injunctions for infringement of innovation patents is permitted on the same terms as for a standard patent. The study shows that divisional-innovation patents are clearly being used, as the citalopram/escitalopram evergreening patent strategy shows, to fill an enforcement void during the time that the parent-standard patents are not yet in force.

\section{The proposed TPPA}

Our data show an urgent need for higher standards for patent systems to reduce the widespread practice of evergreening branded medicines. This, of course, directly conflicts with the ambit claims put forward by US negotiators in the context of international "free" trade treaties. While the Trans Pacific Partnership Agreement (TPPA) is being negotiated in secret a leaked version of draft US text ${ }^{128}$ includes, as the first requirement with respect to patents, that

"patents shall be available for any new forms, uses, or methods of using a known product; and a new form, use, or method of using a known product may satisfy the criteria for patentability, even if such invention does not result in the enhancement of the known efficacy of that product. " (Article 8(1), emphasis added)

It seems likely that this wording comes straight from the brand pharmaceutical industry. It directly addresses the issue that evergreening patents often provide little or no improvement in measurable health outcomes. It attempts to pre-empt national parliaments addressing the evergreening issue by raising the inventiveness requirement from a scintilla to something which better balances the costs and benefits of patent systems.

The TRIPS Agreement left considerable flexibility for nations to shape patent law to suit their national circumstances. Nothing in TRIPS would prevent requiring a sufficiently high inventive step so that a patent system delivered a positive economic outcome for each

\footnotetext{
${ }^{128}$ http://keionline.org/sites/default/files/tpp-10feb2011-us-text-ipr-chapter.pdf (accessed 11 Nov 2012).
} 
nation. Post-TRIPS "trade" treaties seek to remove these flexibilities. In particular the TPPA seeks to embed a precise approach for inventiveness which currently delivers a very low standard. Such initiatives suggest that raising the height of the inventive step is urgent.

Beyond patents, trademarks play a critical role in developing consumer loyalty and maintaining this after patent expiry. In the case of EFEXOR-XR, pharmacist evidence that older consumers would become confused by changes in packaging was one of two arguments that were critical in the judicial decision to delay market entry by over two years. Such possible confusion, however, also raises the policy issue of whether it is sensible to allow such expensive yet essential products to be trademarked beyond carrying the logo of the company.

Under Australia's Pharmaceutical Benefits Scheme (PBS) many medicines are subsidised by taxpayers, allowing minimum estimates to be made for the cost of delayed generic market entry. The case studies show that the cost of evergreening to the Australian government can be significant in any individual case. Given widespread use of the practice of evergreening the cumulative cost to the taxpayer is substantial.

The generic pharmaceutical industry plays an important role in providing the balance that is so critical to good patent policy. If companies specialising in brand medicines are able to delay generic entry, even by a few months, this reduces revenue for generic companies and raises the cost of the patent system. Recent changes to PBS pricing policy - designed to deliver the benefits of lower generic prices more quickly - have put further pressure on the generics industry. Policies which would reduce the frequency of grant of low-quality patents would offset this, returning a greater incentive to the important generics industry.

India has developed a patent law which refuses patents to such minor compositional variants unless there is an improvement in health outcomes. The WHO has put forward similar proposals. Adopting such approaches would clearly be welfare-enhancing. 


\section{References}

Amin, T. and A.S. Kesselheim (2012), 'Secondary patenting of branded pharmaceuticals: a case study of how patents on two HIV drugs could be extended for decades', Health Affairs 31 (10): 2286-2294.

Bouchard, R.A., R.W. Hawkins, R. Clark, R. Hagtvedt, and J. Sawani (2010), 'Empirical analysis of drugapproval-drug patenting linkage for high value pharmaceuticals', Northwestern Journal of technology and Intellectual Property 8 (2): 174-227.

Bouchard, R.A., J. Swani, C. McLelland, M. Sawicka, and R.W. Hawkins (2009), 'The Pas de Deux of Pharmaceutical Regulation and Innovation: Who's Leading Whom?', Berkeley Technology Law Journal 24: 1461-1522.

Burdon, M. and K. Sloper (2003), 'The Art of Using Secondary Patents to Improve Protection', Journal of Medical Marketing 3 (3): 226-238.

Christie, A.F., C. Dent, P. Mclntyre, L. Wilson, and D.M. Studdert (2013), 'Patents Associated with High-Cost Drugs in Australia', PLOS One 8 (4): 1-7.

European Commission (2009), Final Report: Competition Inquiry into the Pharmaceutical Sector, Brussels: European Commission.

Furrow, M.E. (2008), 'Pharmaceutical Patent Life-Cycle Management after KSR v. Teleflex', Food and Drug Law Journal 63 (1): 275-320.

Gleeson, D., R. Lopert, and P. Reid (2013), 'How the Trans Pacific Partnership Agreement could undermine PHARMAC and threaten access to affordable medicines and health equity in New Zealand', Health Policy in press.

Goldacre, B. (2012), Bad Pharma, London: Fourth Estate.

Hemphill, C.S. and B.N. Sampat (2012), 'Evergreening, Patent Challenges, and Effective Market Life in Pharmaceuticals', Journal of Health Economics 31: 327-339.

Holovac, M.A. (2004), 'A balancing act in the United States Drug Industry: pioneer and generic drugs, the Orange Book, marketing protection and the US consumer', World Patent Information 26: 123-129.

IP Australia (2009), Toward a Stronger and More Efficient IP Rights System: Proposed Reforms, Canberra: IP Australia.

IPAC (1984), Patents, Innovation and Competition in Australia, Canberra: Industrial Property Advisory Committee (now available at http://www.acip.gov.au/reviews other.html).

Kapczynski, A., C. Park, and B. Sampat (2012), 'Polymorphs and Prodrugs and Salts (Oh My!): An Empirical Analysis of "Secondary" Pharmaceutical Patents', PLOS One 7 (12): e49470.

Kotze, A. (2012), 'Reining in patent term extensions for related pharmaceutical products post-Photocure and Ortho-McNeil', Northwestern University Law Review 106 (3): 1419-1450.

Kvesic, D.Z. (2008), 'Product Lifecycle Management: Marketing Strategies for the Pharmaceutical Industry', Journal of Medical Marketing 8: 293-301.

Lawson, C. (2008), 'Quantum of obviousness in Australian patent laws', Australian Intellectual Property Journal 19: 43-65. 
Light, D.W. and R. Warburton (2011), 'Drug R\&D costs questioned', Genetic Engineering and Biotechnology News: 6-7.

Machlup, F. (1958), An Economic Review of the Patent System (Study No.15 of the U.S. Senate Subcommittee on Patents, Trademarks and Copyrights), Washington, D.C.: US Government Printing Office.

Murti, Y., B. Yogi, S. Gupta, and D. Pathak (2008), 'Me-Too Drugs : Good or Bad?'. http://www.pharmainfo.net/reviews/me-too-drugs-good-or-bad

O'Neil, M.J. (2010), Merck Index: An Encyclopedia of Chemicals, Drugs, and Biologicals, 14th ed. New Jersey: Wiley.

Ouellette, L.L. (2010), 'How Many Patents Does It Take To Make a Drug? Follow-On Pharmaceutical Patents and University Licensing', Michigan Telecommunications and Technology Law review 17: 299-336.

Sopko Jr, M.A., M.J. Ehret, and M. Grgas (2008), 'Desvenlafaxine: Another "Me Too" Drug?', The Annals of Pharmacotherapy 42: 1439-1446. 